\title{
FORMULATION AND EVALUATION OF NIOSOMAL IN SITU GEL OF PREDNISOLONE SODIUM PHOSPHATE FOR OCULAR DRUG DELIVERY
}

\author{
PRAVEEN D. CHAUDHARI ${ }^{1}$, UJWALA S. DESAI ${ }^{*}$
}

1Department of Pharmaceutics, PES' Modern College of Pharmacy, Savitribai Phule Pune University, Sector no. 21, Yamunanagar, Nigdi, Pune 411044, Maharashtra, India

Email: ujudesai@gmail.com

Received: 06 Nov 2018, Revised and Accepted: 09 Jan 2019

\section{ABSTRACT}

Objective: The main purpose of the study was to develop niosomal in situ gel of prednisolone sodium phosphate (PSP) with increased bioavailability (enhanced permeation) and sustained action (drug retention at the target site).

Methods: Using different ratios of span 60 and cholesterol (chol), niosomes were prepared by thin film hydration method and optimized by evaluating different parameters like drug content, entrapment efficiency, particle size and in vitro drug diffusion study. The niosomal pellets were further incorporated in in situ gel, prepared by the cold method and further optimized by parameters like gelling parameters, mucoadhesive strength and in vitro, in vivo drug release study.

Results: The optimized niosomal formulation containing span 60 and chol in equal proportion (1:1) showed better drug content (DC) i.e. $86.3 \pm 0.39 \%$ and entrapment efficiency (EE) i.e. $83.4 \pm 0.22$ with vesicle size of $465 \pm 0.24 \mathrm{~nm}$. The in vitro drug diffusion study indicated t90 value of $490 \mathrm{~min}$ thus proving sustained action of the formulation. The optimized in situ gel containing poloxamer 407 (P407) and poloxamer 188 (P188) in the ratio of 1:2.7 showed gelation temperature at $37^{\circ} \mathrm{C}$ (physiological temperature of the body) and t90 value of $10 \mathrm{~h}$ thus depicting sustained action. The increased area under curve (AUC) value by 1.75 folds proved increased bioavailability of the drug.

Conclusion: Thus sustained drug delivery with increased bioavailability was designed for prednisolone sodium phosphate for the treatment of ocular inflammation.

Keywords: Niosomes, in situ gel, Sustained drug release, Ocular, Prednisolone sodium phosphate

(C) 2019 The Authors. Published by Innovare Academic Sciences Pvt Ltd. This is an open-access article under the CC BY license (http://creativecommons.org/licenses/by/4.0/) DOI: http://dx.doi.org/10.22159/ijap.2019v11i2.30667

\section{INTRODUCTION}

Poor bioavailability of ocularly administered drug can be attributed to factors which include tear dynamics (blinking reflex and tear turnover) [1], non-productive absorption, transient residence time in the cul-de-sac, relative impermeability through corneal epithelial membrane, rapid precorneal elimination, drainage by gravity, frequent installation, enzymatic metabolism, nasolacrimal drainage, and the absence of controlled release [2-8]. Due to these physiological and anatomical constraints, a very small fraction of the administered drug (approx.1\% or even less) of the instilled dose is available for ocular absorption [9-10]. Frequent dosing of drugs thus becomes a necessity to achieve the therapeutic concentration at the targeted site. This often results in the corresponding increase in local and systemic side effects. The high dose and dosing frequency cause unavoidable systemic side effects like stomach upset and disturbed GI motility [11]. The systemic route can overcome this but due to the presence of the blood-aqueous barrier and blood-retinal barrier, it ultimately leads to high loading dose at the target site. Various approaches, like viscosity enhancement, use of mucoadhesive, particulate drug delivery, vesicular drug delivery, prodrugs, and other controlled systems like ocuserts, iontophoresis, bioadhesive gels, ocular insert, contact lenses etc. are being explored [3,12-14].

Vesicular systems (niosomes and liposomes) can act as drug reservoirs. Niosomes offers advantages like no variation in the purity of surfactants, cost-effective, chemically stable, low toxicity because of their non-ionic nature, flexibility in the structure which helps them to form micelles and can improve the performance of the drug via better availability and controlled delivery at a particular site. Niosomes are capable of encapsulating both hydrophilic and lipophilic drugs and can serve as effective drug carriers [15]. However, nonionic surfactant vesicles may promote drug absorption by preferentially modifying the permeability characteristics of the conjunctival and scleral membranes as surfactants in lower concentration are used as penetration enhancers $[16,17]$.
The in-situ gel is drug delivery system that is in sol form before administration in the body, but undergo gelation with the change in physiological conditions, to form sol to gel (from the lat. gelufreezing, cold, ice or gelatus-frozen, immobile). Vesicular systems in combination with mucoadhesive polymers show a controlled as well as a prolonged effect $[18,19]$. Prolonging the drug contact time with the surface of the eye can also increase their penetration through the cornea, hence increasing the accessibility of the drug to aqueous humor [20-22]. This can be accomplished by use of bioadhesive polymer which helps the drug to remain adhered to eye surface by forming a noncovalent bond for a long period of time thus preventing the drug from undergoing nasolachrymal drainage. This will reduce the amount of drug (dose of the drug) and the dose frequency necessary for therapeutic effect. A reduction in dose will help to reduce the incidence of systemic side-effects.

PSP is corticosteroid drug effective in the treatment of steroid responsive inflammatory conditions such as allergic conjunctivitis, acne rosacea, superficial punctate keratitis, herpes zoster keratitis, iritis, cyclitis etc. PSP decreases inflammation by suppressing migration of polymorphonuclear leukocytes and reversing increasing capillary permeability for the treatment [23]. The major drawback of steroid treatment is the side effects associated with it if used over a long period of time.

The aim of the present investigation was to achieve the increased permeation of PSP by loading in niosome vesicles and improve its retention time at the particular site of action by incorporating the drug-loaded niosome into in situ gel which significantly reduces dosage frequency hence increase patient compliance.

\section{MATERIALS AND METHODS}

\section{Materials}

PSP was obtained from Sai Life Sciences, Pune. Span 60 from Loba chemicals, chol from Analab fine chemicals, P407and P188 from 
BASF Chemicals were procured. All the chemicals used were of analytical grade.

\section{Preparation of niosomes}

\section{Ethanol injection method}

Niosomes containing PSP was prepared by modified ethanol injection method. Surfactant and chol in different ratios were dissolved in methanol. The resulting solution was slowly injected using microsyringe at a rate of $0.25 \mathrm{ml} / \mathrm{min}$ into $15 \mathrm{ml}$ of Phosphate buffer (PBS) pH 7.4 containing PSP. The solution was stirred continuously on a magnetic stirrer (Remi, 2MLH) and the temperature was maintained above $60^{\circ} \mathrm{C}$. Stirring continued for 1$1.5 \mathrm{~h}$. Vaporization of solvent takes place, resulting in spontaneous vesiculation and formation of unilamellar spherical niosomes [24].

\section{Thin film hydration}

Accurately weighed quantity of surfactant and chol in different molar ratios (table 1) were dissolved in chloroform and methanol mixture in a round bottom flask. The solvent mixture was evaporated in a rotary flash evaporator (Trident labotech, Thane) under a vacuum of 20 inches of $\mathrm{Hg}$ at a temperature of $25 \pm 2{ }^{\circ} \mathrm{C}$ and the flask rotated at $100 \mathrm{rpm}$ until a smooth, dry lipid film was obtained. The film was hydrated with $10 \mathrm{ml}$ of PBS pH 7.4 containing $25 \mathrm{mg}$ prednisolone sodium phosphate drug for $45 \mathrm{~min}$ at $60^{\circ} \mathrm{C}$ with gentle shaking on a water bath. The niosomal suspension was further stored at $2-8^{\circ} \mathrm{C}$ for $24 \mathrm{~h}$ [24].

Batches of niosomes were prepared to vary in the method of preparation (table 1), the combination of surfactants (table 2), an individual surfactant in different concentrations (table 3), selection of surfactant grade (table 4) and the ratio of chol and span 60 (table
5) respectively. Optimization was carried out on the basis of DC, EE, vesicle size and in vitro drug diffusion study.

\section{Preparation of niosomal in situ gel}

The "Cold method" was adopted for preparing poloxamer-based gels. The required amounts of P407 and P188 for each formulation were carefully weighed and placed in a flat bottomed vial. After the addition of the required amount of $0.9 \% \mathrm{NaCl}$ solution for isotonicity, the vial was placed at $4{ }^{\circ} \mathrm{C}$ until P407 and P188 were dissolved completely and a clear solution was obtained. In the study, P407 and P188 concentrations in sols or gels were expressed as the weight percentage $(\% \mathrm{w} / \mathrm{v})$. The equivalent amount of niosomal pellets obtained from the freeze-drying process was added into the gel formulation along with $100 \mathrm{mg}$ of the synthesized polymer [25] and benzalkonium chloride $(0.01 \%)$ to form final formulation of niosomal in situ gel. Preliminary blank batches were prepared without niosomes and bioadhesive polymer to find out the ratio of P407 and P188 exhibiting gelation temperature near to $37^{\circ} \mathrm{C}$ [26].

\section{Evaluation of niosomes}

\section{Drug content}

In $1 \mathrm{ml}$ of niosomal buffer solution, $2 \mathrm{ml}$ methanol was added and further volume was made up by distilled water. Addition of methanol cause breakdown of niosomes and hence drug could freely get dissolve in a solvent. Each of this solution was further diluted according to the requirement by distilled water. Absorbance was measured on UV-visible spectrophotometer (Shimatzo UV visible 1650, Japan) at $247 \mathrm{~nm}$ [24]. Drug content was determined by using the formula

Percent drug conten $=\frac{\text { Test abs. } \times \text { Standard Conc. }}{\text { Standard abs. } \times \text { weight of drug }} \times$ Dilution factor $\times 100$

Table 1: Composition of trial batches for method selection

\begin{tabular}{|c|c|c|c|c|c|c|c|}
\hline Batch code & M1 & M2 & M3 & M4 & M5 & M6 & M7 \\
\hline Chol (mg) & 25 & 25 & 25 & 25 & 25 & 25 & - \\
\hline Span 60 (mg) & 25 & - & - & 25 & - & - & - \\
\hline Tween 20 (mg) & - & 25 & - & - & 25 & - & - \\
\hline Tween 80 (mg) & - & - & 25 & - & - & 25 & - \\
\hline Span 80 (mg) & - & - & - & - & - & - & 25 \\
\hline Methanol (ml) & 1 & 1 & 1 & 1 & 1 & 1 & 1 \\
\hline $\mathrm{CHCl}_{3}(\mathrm{ml})$ & 4 & 4 & 4 & 4 & 4 & 4 & 4 \\
\hline Drug (mg) & 25 & 25 & 25 & 25 & 25 & 25 & 25 \\
\hline Buffer (ml) & 7.5 & 7.5 & 7.5 & 7.5 & 7.5 & 7.5 & 7.5 \\
\hline Technique & \multicolumn{3}{|c|}{ Ethanol injection method } & \multicolumn{4}{|c|}{ Thin film hydration technique } \\
\hline
\end{tabular}

Table 2: Composition of trial batches for combination surfactants

\begin{tabular}{|c|c|c|c|c|c|c|}
\hline Batches & C1 & $\mathrm{C2}$ & C3 & C4 & $\mathrm{C5}$ & C6 \\
\hline Chol (mg) & 25 & 25 & 25 & - & - & - \\
\hline Span 60 (mg) & 12.5 & - & - & 12.5 & 12.5 & - \\
\hline Span 80 (mg) & 12.5 & 12.5 & - & - & - & 12.5 \\
\hline Tween 20 (mg) & - & 12.5 & 12.5 & 12.5 & - & - \\
\hline Tween 80 (mg) & - & - & 12.5 & - & 12.5 & 12.5 \\
\hline Methanol (ml) & 1 & 1 & 1 & 1 & 1 & 1 \\
\hline $\mathrm{CHCl}_{3}(\mathrm{ml})$ & 4 & 4 & 4 & 4 & 4 & 4 \\
\hline Drug (mg) & 25 & 25 & 25 & 25 & 25 & 25 \\
\hline Buffer (ml) & 7.5 & 7.5 & 7.5 & 7.5 & 7.5 & 7.5 \\
\hline
\end{tabular}

Table 3: Composition of trial batches for shortlisting surfactant

\begin{tabular}{|c|c|c|c|c|}
\hline & S1 & S2 & S3 & S4 \\
\hline Chol (mg) & 25 & 25 & 25 & - \\
\hline Span 60 (mg) & 25 & - & - & - \\
\hline Tween 20 (mg) & - & 25 & - & - \\
\hline Tween 80 (mg) & - & - & 25 & - \\
\hline Span 80 (mg) & - & - & - & 25 \\
\hline Methanol (ml) & 1 & 1 & 1 & 1 \\
\hline $\mathrm{CHCl}_{3}(\mathrm{ml})$ & 4 & 4 & 4 & 4 \\
\hline Drug (mg) & 25 & 25 & 25 & 25 \\
\hline Buffer (ml) & 7.5 & 7.5 & 7.5 & 7.5 \\
\hline
\end{tabular}


Table 4: Composition of trial batches for selection of surfactant grade

\begin{tabular}{|c|c|c|c|c|c|c|c|c|c|c|}
\hline Batches & CS1 & CS2 & CS3 & CS4 & CS5 & CSS1 & CSS2 & CSS3 & CSS4 & CSS5 \\
\hline Chol (mg) & 25 & 25 & 25 & 25 & 25 & 25 & 25 & 25 & 25 & 25 \\
\hline Span $60(\mathrm{mg})$ & 25 & 50 & 75 & 100 & 125 & - & - & - & - & - \\
\hline Span 80 (mg) & - & - & - & - & - & 25 & 50 & 75 & 100 & 125 \\
\hline Methanol (ml) & 1 & 1 & 1 & 1 & 1 & 1 & 1 & 1 & 1 & 1 \\
\hline $\mathrm{CHCl}_{3}(\mathrm{ml})$ & 4 & 4 & 4 & 4 & 4 & 4 & 4 & 4 & 4 & 4 \\
\hline Drug (mg) & 25 & 25 & 25 & 25 & 25 & 25 & 25 & 25 & 25 & 25 \\
\hline Buffer $(\mathrm{ml})$ & 10 & 10 & 10 & 10 & 10 & 10 & 10 & 10 & 10 & 10 \\
\hline Chol: surfactant ratio & $1: 1$ & $1: 2$ & $1: 3$ & $1: 4$ & $1: 5$ & $1: 1$ & $1: 2$ & $1: 3$ & $1: 4$ & $1: 5$ \\
\hline
\end{tabular}

Table 5: Composition of trial batches for selection of ratio between chol and surfactant

\begin{tabular}{|c|c|c|c|c|c|c|c|c|c|c|c|c|}
\hline Batches & CS6 & CS7 & CS8 & CS9 & CS10 & CS11 & CS12 & CS13 & CS14 & CS15 & CS16 & CS17 \\
\hline Chol (mg) & 25 & 25 & 25 & 25 & 25 & 50 & 62.5 & 75 & 87.5 & 150 & 200 & 250 \\
\hline Span 60 (mg) & 150 & 175 & 200 & 225 & 250 & 25 & 25 & 25 & 25 & 150 & 200 & 250 \\
\hline Methanol (ml) & 1 & 1 & 1 & 1 & 1 & 1 & 1 & 1 & 1 & 1 & 1 & 1 \\
\hline $\mathrm{CHCl}_{3}(\mathrm{ml})$ & 4 & 4 & 4 & 4 & 4 & 4 & 4 & 4 & 4 & 4 & 4 & 4 \\
\hline Drug (mg) & 25 & 25 & 25 & 25 & 25 & 25 & 25 & 25 & 25 & 25 & 25 & 25 \\
\hline Buffer (ml) & 10 & 10 & 10 & 10 & 10 & 10 & 10 & 10 & 10 & 10 & 10 & 10 \\
\hline Chol: Surfactant ratio & $1: 6$ & $1: 7$ & $1: 8$ & 1:9 & $1: 10$ & $2: 1$ & $2.5: 1$ & $3: 1$ & $3.5: 1$ & $1: 1$ & $1: 1$ & $1: 1$ \\
\hline
\end{tabular}

\section{Entrapment efficiency}

Prepared PSP niosomes were separated from the unentrapped drug by centrifugation at $2750 \mathrm{rpm}$ for $60 \mathrm{~min}$ using the cooling centrifuge. Cooling centrifuge (Laby instruments, India) was used as niosomes are stable and stored at the refrigerated condition that is at $2-8{ }^{\circ} \mathrm{C}$. The absorbance of the supernatant was taken after appropriate dilution at $247 \mathrm{~nm}$. Settled pellets were dispersed in distilled water to get a clear solution. After appropriate dilutions, absorbance was recorded [27]. The entrapment efficiency was calculated through the following relationship,

$$
\% \mathrm{EE}=\frac{\text { Entrapped drug }}{\text { Entrapped drug + Drug in supernatant }} \times 100
$$

\section{Vesicle size distribution}

The average vesicle size of niosomes was measured by the method of laser light diffraction using Nanophox NX0088. Prior to measurements, about $50 \mathrm{mg}$ of each sample was dispersed with 100 $\mathrm{ml}$ of hexane and signal to noise ratio was measured in order to eliminate error if any. The vesicle size distributions were estimated by setting the intensity of the scattered light at a wavelength of 750 $\mathrm{nm}$ and the scattering angle $(\theta)$ of $90[26]$.

\section{In vitro release study}

Drug release from niosomes was studied using a dialysis method. Dialysis bags were soaked before use in distilled water at room temperature for $12 \mathrm{~h}$ to remove the preservative, followed by rinsing thoroughly in distilled water. In vitro release of PSP from niosomes was conducted by dialysis in a dialysis sac made up of a cellophane membrane (Sigma-Aldrich) with $100 \mathrm{ml}$ of PBS (pH 7.4) at $37{ }^{\circ} \mathrm{C}$. Two ends of the dialysis sac were tightly bound with threads. The sac was hung inside a beaker with the help of a glass rod so that the portion of the dialysis sac with the formulation dipped into the buffer solution. The beaker was kept on a magnetic stirrer (Remi, 2MLH) and stirring was maintained at $100 \mathrm{rpm}$ at 37 ${ }^{\circ} \mathrm{C}$ with thermostatic control. Samples were collected every at 15 min, $30 \mathrm{~min}, 45 \mathrm{~min}, 1 \mathrm{~h}, 2 \mathrm{~h}, 3 \mathrm{~h}$ and further $1 \mathrm{hr}$ interval over a period of $6 \mathrm{~h}$ and assayed spectrophotometrically for drug released and the sampled volume of buffer maintained at the same temperature. An equal volume of fresh release medium was replaced at the same time intervals. The diffusion data were analyzed for calculating the amount of drug released and percentage drug released at different time intervals [25].

\section{Release kinetics of drug}

The kinetics of the drug release was evaluated by the model fitting method using PCP Disso v3 software and the model with the highest correlation coefficient amongst them was considered to be the best model for the particular formulation

\section{Fourier transform infrared spectroscopy (FTIR)}

The infrared spectrum of prednisolone sodium phosphate was determined on Fourier Transform Infrared Spectrophotometer (FT/IR 4100, Jasco) using potassium bromide ( $\mathrm{KBr}$ ) dispersion method. The baseline correction was done using dried KBr. The samples to be analyzed and $\mathrm{KBr}$ were previously dried in the oven for $30 \mathrm{~min}$ and mixed thoroughly in 1:300 (sample: $\mathrm{KBr}$ ) ratio in a glass mortar. These samples were then placed in a sample holder and scans were obtained at a resolution of $2 \mathrm{~cm}^{-1}$ from 4000 to 400 $\mathrm{cm}^{-1}[28]$.

\section{Differential scanning calorimetry (DSC)}

DSC measurements were performed on a differential scanning calorimeter containing an intra-cooler (DSC Mettler STAR SW 9.20, Switzerland). Nitrogen gas was purged $(50 \mathrm{ml} / \mathrm{min})$ to maintain an inert atmosphere. All accurately weighed samples (about 5-10 mg of samples) were placed in a sealed aluminum pan, and the samples were heated under nitrogen gas flow $(20 \mathrm{ml} / \mathrm{min})$ at a scanning rate of $10^{\circ} \mathrm{C}$ per min from 40 to $340{ }^{\circ} \mathrm{C}$. An empty aluminum pan was used as reference [29].

\section{Optical microscopy}

Optical microscopy of the drug sample was carried out by using a Digital Microscope (Motic). A very slight quantity of the niosomal sample solution was spread on the glass slide. This slide was focused under various magnification lenses and the images were captured [30].

\section{Zeta potential determination}

Niosomal dispersion $(0.5 \mathrm{ml})$ was diluted to $50 \mathrm{ml}$ with distilled water in a glass beaker with constant stirring. Zeta-potential of the resulting suspension was determined using the Zetasizer (model: Nano ZS, Malvern Instruments, Westborough, MA, USA) Electrophoretic mobility $(\mu \mathrm{m} / \mathrm{s})$ was measured using small volume disposable zeta cell and converted to zeta potential by inbuilt software using Helmholtz-Smoluchowski equation [26].

\section{Polydispersity index (PDI)}

The PDI determination was using photon correlation spectroscopy with in-built Zetasizer (model: Nano ZS, Malvern Instruments, Westborough, MA, USA) at $633 \mathrm{~nm}$ [26]. The polydispersity index was calculated by

$$
\mathrm{PDI}=\frac{\mathrm{X} 90-\mathrm{X} 10}{\mathrm{X} 50}
$$




\section{Transmission electron microscopy (TEM) analysis}

TEM (Philips CM 200 super twin stem microscope) was used to determine the morphology of the niosomal vesicles. Few drops of the optimized niosomal formulation (CS17) were deposited on a carbon-coated copper grid and examined under a transmission electron microscope [31].

\section{Evaluation parameters in situ gel}

\section{Appearance}

The appearance of the gels was examined for clarity. The clarity of various formulations was evaluated by visual inspection under the black and white background.

\section{pH}

The $\mathrm{pH}$ of each formulation was examined using a digital $\mathrm{pH}$ meter (Equip tronics, EQ610). The $\mathrm{pH}$ meter was first calibrated using buffer solutions of $\mathrm{pH} 4$ and $\mathrm{pH}$ 7. Then gel was taken in a beaker and the $\mathrm{pH}$ was measured [24].

\section{Drug content of in situ gel}

In this study, each formulation $(1 \mathrm{ml})$ was taken in a $100 \mathrm{ml}$ volumetric flasks diluted with distilled water up to the mark. After suitable dilutions, the amount of drug was measured in the formulation by using ultraviolet spectroscopy at $246 \mathrm{~nm}$ [24].

\section{Gelation time}

The Tsol-gel of the formulation was determined by test tube inversion method. Niosomal in situ gel $(2 \mathrm{ml})$ was transferred to a test tube and sealed with paraffin. This test tube was placed in the constant temperature water bath at $35 \pm 1{ }^{\circ} \mathrm{C}$. The sample was examined for gelation [24]

\section{Gelation temperature and gel melting temperature}

The Tsol-gel of the formulation was determined by test tube inversion method. Niosomal in situ gel $(2 \mathrm{ml})$ was transferred to a test tube and sealed with paraffin. This test tube was placed in the constant temperature water bath (Equitron). The temperature of the water bath was increased in increments of 2 ${ }^{0} \mathrm{C}$ and left to equilibrate at each new temperature. However, in the region of Tsol-gel temperature was raised slowly in the increments of $0.5{ }^{\circ} \mathrm{C}$. The formulation was examined for gelation which was said to have occurred when the meniscus would no longer move upon tilting through $90^{\circ}$. Measurements were done in triplicate [32].

The obtained temperature is said to be T1. After attaining the temperature $\mathrm{T} 1$, further heating of gel causes liquefaction of gel and form the viscous liquid and it starts flowing, this temperature is noted as T2 i.e. gel melting temperature.

\section{Gelling capacity}

Determination of in vitro gelling capacity was done by a visual method. Colored solutions (1\% Congo red solution in water) of insitu gel were prepared. The in vitro gelling capacity of prepared formulations was measured by placing $5 \mathrm{ml}$ of the gelation solution (pH 7.4 PBS) in a glass test tube and maintained at $37 \pm 1{ }^{\circ} \mathrm{C}$ temperature. One $\mathrm{ml}$ of colored formulation solution was added with the help of pipette. As the colored solution comes in contact with gelation solution, it was immediately converted into the stiff gel-like structure. The gelling capacity of the solution was evaluated on the basis of the stiffness of the formed gel and time period for which the formed gel remains as such. The in vitro gelling capacity was graded in two categories on the basis of gelation time and time period for which the formed gel remains as such [33].

\section{Texture analysis}

Texture analysis of the prepared gel formulation was done by using Brookefield texture analyzer CT3. The formulations were evaluated for the following parameters.

\section{Gel strength}

The gel strength, which is an indication of the viscosity of the gel at physiological temperature, was measured by measuring the force required for depression of gel at $37^{\circ} \mathrm{C}$ temperature [32].

\section{Mucoadhesive strength}

The mucoadhesive potential of each formulation was determined by measuring a force required to detach the formulation from the conjunctival membrane. The mucoadhesive force expressed as the detachment stress in dynes $/ \mathrm{cm}^{2}$ was determined from the minimum weight that detached the mucosal tissue from the surface of each formulation $[34,35]$.

$$
\text { Mucoadhesive strength }=\frac{\mathrm{mg}}{\mathrm{A}}
$$

Where,

$$
\begin{aligned}
& \mathrm{m}=\text { Weight required for detachment in } \mathrm{g} \\
& \mathrm{g}=\text { acceleration due to gravity }\left(980 \mathrm{~cm} / \mathrm{s}^{2}\right) \\
& \mathrm{A}=\text { area of mucosa exposed }\left(\mathrm{cm}^{2}\right)
\end{aligned}
$$

\section{Spreadability}

The spreadability was evaluated by measuring the distance to which the $10 \mathrm{ml}$ formulation would spread under the influence of specified force applied on gel [24].

\section{Viscosity measurement}

The viscosity of prepared gel formulation was measured by using Brookefield DV-II pro-plus viscometer (Brookefield engineering Labs Inc. Middleboro, USA) equipped with a helipath stand and $\mathrm{T}$ bar spindles. Viscosity measurements were made at variable temperature and variable shear rate. For temperature dependent study, the formulation was subjected to constant shear rate at different temperatures from 25 to $40{ }^{\circ} \mathrm{C}$. During this testing, the temperature was raised gradually by $1{ }^{\circ} \mathrm{C}$ and the viscosity of the sample was measured after attaining the set temperature. Measurements were done in triplicate. Steady shear sweep test was carried out by measuring the viscosity at the constant temperature of $25^{\circ} \mathrm{C}$ and $37{ }^{\circ} \mathrm{C}$ but varying the rotation speed of the spindle from 10 to $100 \mathrm{rpm}$ [32].

\section{In vitro drug diffusion study}

In vitro release studies were carried out using Franz diffusion cell and the temperature was adjusted to $37 \pm 0.5{ }^{\circ} \mathrm{C}$. The prehydrated dialysis membrane (cellophane membrane) was used for the study. Samples were withdrawn at periodic intervals of $0.5,1,2,3,5$ and $6 \mathrm{~h}$ and replaced with fresh simulated tear fluid to maintain sink conditions. The drug content was analyzed using UV-Visible Spectrophotometer at $247 \mathrm{~nm}$ using simulated tear fluid as blank [25]. The apparent diffusion coefficient was calculated by using formula

$$
\text { Dapp }=\frac{\Delta \mathrm{Q}}{\Delta \mathrm{t}} \times \frac{1}{\mathrm{ACo60}}
$$

Where $\Delta \mathrm{Q} / \Delta \mathrm{t}(\mu \mathrm{g} / \mathrm{min})$ is the flux across the corneal tissue. A is the area of diffusion $\left(\mathrm{cm}^{2}\right)$, Co $\left(\mu \mathrm{g} / \mathrm{cm}^{3}\right)$ is the initial concentration of drug in the donor compartment, and 60 is taken as the factor to convert min into second. The flux across the cornea was obtained from the slope of the regression line obtained from the linear part of the curve between the amount permeated $(\mathrm{Q})$ vs time $(\mathrm{t})$ plot.

\section{Ex vivo diffusion study}

Ex vivo drug diffused study was performed for the optimized formulation and marketed formulation by using $5 \mathrm{ml}$ of Franz diffusion cells containing simulated tear fluid. The goat conjunctival epithelium was used for the study. $1 \mathrm{ml}$ of sample was placed in the donor compartment and diffusion study was conducted for $6 \mathrm{~h}$ at $37 \pm 1{ }^{\circ} \mathrm{C}$. Sample $(0.5 \mathrm{ml})$ was withdrawn at $1 / 2 \mathrm{~h}$ for an hour and then every $1 \mathrm{~h}$ and the same quantity of simulated tear fluid was added [26]. 


\section{Pharmacodynamic study}

\section{Primary skin irritation test}

Two healthy albino rabbits were used for the experiment. Animal husbandry was conducted in accordance with the "Guide for the Care and use of Laboratory Animals," National Institute of Health (NIH) publication No.85-23.

Methods: The backs of the animals were cleaned free of fur with a razor at least $4 \mathrm{~h}$ before application of the sample. One ml sample of the least irritant polymer obtained from ex vivo test was then applied to the particular site to an area of skin approximately $1 " \times 1$ " $(2.54 \times 2.54 \mathrm{~cm})$ square. The sample applied site was covered with a nonreactive tape. Animals were returned to their cages. After a $24 \mathrm{~h}$ exposure, the tape was removed and the test sites were wiped with tap water to remove the test sample. At 24 and $72 \mathrm{~h}$ after the test sample application, the test sites were examined for dermal reactions in accordance with the Federal Hazardous Substance Act (FHSA)-recommended Draize scoring criteria (Appendix 1). Primary Irritation Index (P. I. I.) of the test sample was calculated following test completion [36].

\section{In vivo draize eye irritation test}

The Draize test was performed on white albino rabbits. In this test $100 \mu \mathrm{g}$ test sample was placed into the lower cul-de-sac of rabbit's right eye (1.5-2 kg, $13 \mathrm{w}$ of age). The left eye was treated as a control. Rabbits' eyes were observed periodically for redness, swelling and watering of the eye at $1 \mathrm{~h}, 4 \mathrm{~h}$ and every $24 \mathrm{~h}$ for $7 \mathrm{~d}$. Three rabbits were used for the test substance. These parameters were calculated from the weighted score for each part of the rabbit eye such as (cornea, iris, and conjunctiva) and also from the sum of these scores. The maximal average Draize total scores (MAS) are classified into non-irritants $(0<\mathrm{MAS}<0.5)$, slight irritants $(0.5<\mathrm{MAS}<15)$, mild irritants $(15<\mathrm{MAS}<25)$, moderate irritants $(25<\mathrm{MAS}<50)$ and severe irritants $(50<\mathrm{MAS})$ [37]. Approval of the institutional animal ethics committee (Approval No. MCP/IAEC/01/2016) was obtained prior to the commencing of the study from Modern College of Pharmacy, Nigdi, Pune.

\section{Pharmacokinetic study}

The drug pharmacokinetics in the aqueous humor on ocular instillation of the optimized formulation (B) and the drug solution was measured on male New Zealand albino rabbits. Rabbits (2-2.5 $\mathrm{kg}$ ) were kept in cages kept in a light-controlled (alternate night and day cycles, $12 \mathrm{~h}$ each) air-conditioned chamber under controlled humidity $(45 \pm 5 \%)$. All the experimental protocols were approved by the Institutional Animal Ethics Committee (IAEC) of Modern College of Pharmacy, Nigdi, Pune constituted under the guidelines of Committee for the Purpose of Control and Supervision of Experiment on Animals (CPCSEA, India) with protocol approval number MCP/IAEC/01/2016.

\section{HPLC analysis of prednisolone sodium phosphate}

The quantitative determination of PSP pharmacokinetics in the rabbit aqueous humor was based on a previously validated HPLC method [31]. A reversed-phase HPLC-UV method was used to measure PSP in aqueous humor. The HPLC (Water 600) apparatus consisted of quaternary (gradient system), HPLC pump (isocratic) equipped with $30 \mathrm{w}$ high resolution UV/Vis detector DATA ACE Chromatography Software (version 1.50) integrator software and a Grace smart RP C18 column $(4.6 \mathrm{~mm} \times 250 \mathrm{~mm}$ and $10 \mathrm{~mm}$ particle size).
The mobile phase was prepared by mixing $2.5 \mathrm{ml}$ of isopropanol with $0.2 \mathrm{ml}$ of phosphoric acid and diluting with deionized water to $90 \mathrm{ml}$. The $\mathrm{pH}$ was adjusted to 3.0 with $1 \mathrm{M} \mathrm{NaOH}$ and then diluted further to $100 \mathrm{ml}$. The mobile phase was degassed and filtered through 0.45 -micron nylon filters. The flow rate of the mobile phase was set at $1 \mathrm{ml} / \mathrm{min}$. The detector was set at $246 \mathrm{~nm}$ (absorption maxima of PSP). The injection volume was $20 \mu \mathrm{l}$; run time was 10 min. The calibration concentration ranges for the standards were 0.050 to $1.0 \mu \mathrm{g} / \mathrm{ml}$. An internal standard 6-alpha-methylprednisolone was added to every standard and sample [38].

\section{Study design}

A two treatment, non-blind, randomized, parallel design was adopted to compare the drug pharmacokinetics in the rabbit aqueous humor following ocular instillation of the optimized niosomal in situ gel (B). Twelve rabbits were randomly divided into two groups. The niosomal in situ gel (B) was instilled $(50 \mu \mathrm{l})$ in the lower conjunctival sac of the right eye of each rabbit belonging to the first group (Treatment $\mathrm{A}$ ) while the same volume of the drug solution was applied to those of the second group (Treatment B). The rabbits were systemically anaesthetized with ketamine hydrochloride (intramuscular injection, $50 \mathrm{mg} / \mathrm{kg}$ ). At $5 \mathrm{~min}$ intervals, the formulation was instilled into the eye using a micropipette. At $0.5,1,2,4$, and $8 \mathrm{~h}$ post-instillation, the rabbits were locally anaesthetized (benoxinate $\mathrm{HCl}, 0.4 \% \mathrm{w} / \mathrm{v}$ ) and aqueous humor samples $(0.15 \mathrm{ml})$ were withdrawn by anterior chamber paracentesis [39].

Aqueous humor samples were stored at $-20^{\circ} \mathrm{C}$ until HPLC analysis. Prior to HPLC analysis, the thawed aqueous humor samples were spiked with 6 alpha methylprednisolone. In order to precipitate the associated proteins, the spiked samples $(0.1 \mathrm{ml})$ were vortex mixed $(30 \mathrm{~s})$ with acetonitrile $(0.2 \mathrm{ml})$. Following centrifugation $(15 \mathrm{~min}$, $12000 \mathrm{rpm})$, the drug content in the organic phase layer was determined by HPLC.

\section{Pharmacokinetic analysis}

The graph of concentration of prednisolone sodium phosphate (mean \pm SD) in the rabbit aqueous humor was plotted against time. The maximum drug concentration ( $\mathrm{Cmax}$, in $\mu \mathrm{g} / \mathrm{ml}$ ) and the time to reach Cmax (Tmax, in h) were directly obtained from the individual subject curves. The mean residence time (MRT, in h) was estimated using graph prism ${ }^{\circledR}$ software. The area under the aqueous humor concentration-time curve (AUC, in $\mu \mathrm{g} / \mathrm{h} / \mathrm{ml}$ ) was calculated using the trapezoidal rule method. The results were statistically evaluated, using one-way ANOVA, at $\mathrm{P}<0.05$. The increase in the ocular drug bioavailability (folds) was estimated by dividing the AUC of the niosomal in situ gel (B) over that of the drug solution.

\section{Sterility test}

The formulation was sterilized by membrane filtration method and was incubated with different culture media like soybean casein digest medium and fluid thioglycate medium for a period of $14 \mathrm{~d}$ and observed for the presence of microbial growth if any [33].

\section{Stability study}

On the ICH, Harmonized Tripartite Guidelines on stability testing of new drug substance and product, fundamental recommendations are summarized.

For the drug substances intended for storage in a refrigerator are given in table 6.

Table 6: ICH guidelines for the drug substances intended for storage in a refrigerator.

\begin{tabular}{lll}
\hline Study & Storage condition & Time period \\
\hline Long term & $5{ }^{\circ} \mathrm{C} \pm 3{ }^{\circ} \mathrm{C}$ & $12 \mathrm{mo}$ \\
Accelerated & $25{ }^{\circ} \mathrm{C} \pm 2{ }^{\circ} \mathrm{C} / 60 \% \mathrm{RH} \pm 5 \% \mathrm{RH}$ & $6 \mathrm{mo}$ \\
\hline
\end{tabular}

In order to determine the stability of gels, the samples were kept in airtight glass vials packed by aluminum foil. The niosomal in situ gels were stored at $25{ }^{0} \mathrm{C} \pm 2{ }^{0} \mathrm{C} / 60 \% \pm 5 \%$ RH for 6 mo [40]. These samples were evaluated for drug content, gelation temperature and 
physical characteristics. Samples were also stored at $5{ }^{\circ} \mathrm{C} \pm 3{ }^{\circ} \mathrm{C}$ for 3 mo. These samples were also evaluated for drug content, gelation temperature, and physical characteristics.

\section{Statistical analysis}

The obtained data were analyzed using the one-way analysis of variance $($ ANOVA) test $(\mathrm{P}<0.05)$ was considered as an estimate of significance while evaluating the degree of difference between various formulations.

\section{RESULT AND DISCUSSION}

Optimization of niosomes on the basis of DC, EE and vesicle size

\section{Method selection}

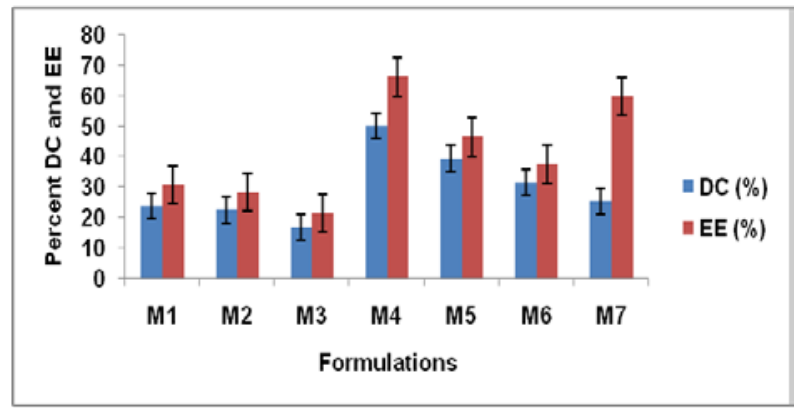

Fig. 1: Graph of DC and EE of preliminary batches for method selection data expressed mean $\pm S D(n=3)$

The niosomes were prepared by two methods namely thin film hydration and ethanol injection method. It was observed that the DC and $\mathrm{EE}$ of niosomes prepared by thin film hydration method were significantly $(\mathrm{p}<0.05)$ higher than of niosomes prepared by the ethanol injection method (fig. 1). In addition to this, niosomes were also evaluated on the basis of their morphology and appearance by motic digital microscopy. Niosomes prepared by thin film hydration technique were spherical and uniform in size. Hence thin film hydration technique was selected for niosomes preparation. Similar results were obtained in salbutamol sulphate liposomes preparation by Honmane SM et al. 2014, where entrapment efficiency was higher for liposomes prepared by thin film hydration technique.

\section{Combination of surfactants}

Niosomes were evaluated for the combined effect of surfactants. By preparing niosomes using a single surfactant and in combination, DC and EE were calculated (fig. 2). It was observed that the use of surfactants in combination did not show a significant effect on DC and EE. The drug content and encapsulation efficiency depended on the HLB value of the mixture of surfactants used. The higher HLB of the mixture of surfactants with respect to individual surfactant reduced its potential in solubilizing and thus entrapping the PSP molecule. The results coincide with the previous study by Taymouri S et al. 2016where effect of different surfactants on physical properties of carvedilol nanoniosomes was studied. Hence single surfactant niosomes were prepared instead of a combination to prevent interaction.

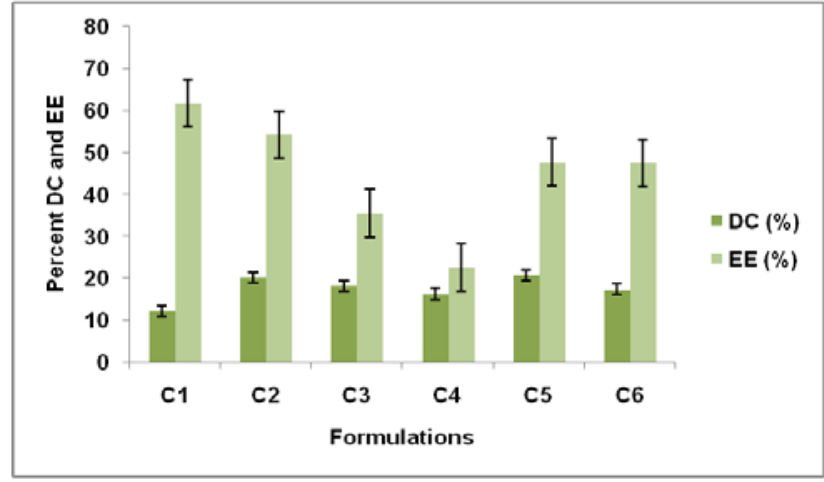

Fig. 2: Graph of DC and EE of trial batches for the combination of surfactants data expressed mean $\pm \operatorname{SD}(n=3)$

\section{Selection of surfactants}

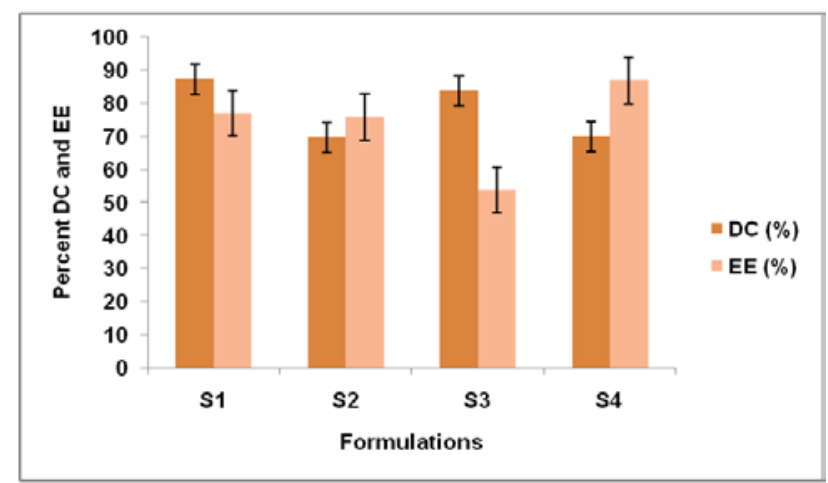

Fig. 3: Graph of DC and EE of trial batches for selection of surfactants data expressed mean $\pm \operatorname{SD}(n=3)$

Four surfactants used during formulation were span 60 , span 80 , tween 20 and tween 80 to prepare niosomes. It was observed that use of spans showed significantly $(\mathrm{p}<0.05)$ higher DC and entrapment efficiency over tweens (fig. 3 ). The probable reason behind this is the Hydrophilic-Lipophilic Balance (HLB) value. HLB is a dimensionless parameter, which is the indication of the solubility of the surfactant molecule. Surfactants with HLB between 4 and 8 can be used for the preparation of vesicle [41]. Hydrophilic surfactants with an HLB value ranging from 14 to 17 are not suitable to form a bilayer membrane due to their high aqueous solubility. However, with the addition of an optimum level of chol, niosomes are indeed formed from Tween 20 (HLB value $=16.7$ ). Spans possess lower HLB which makes the drug entrapment of steroid drug moiety more efficient. The result was found to be in agreement with previous data reported by Shaji J et al. 2016 and Taymouri S et al. 2016 which indicated that lower the HLB of the surfactant; the higher will be the entrapment efficiency.

\section{Selection of surfactant grade}

Table 7: DC, EE, and vesicle size for the selection of surfactant grade

\begin{tabular}{llll}
\hline Batch code & DC (\%) & EE $\mathbf{~ ( \% ) ~}^{*}$ & Vesicle size (nm) $^{*}$ \\
\hline CS1 & $60.16 \pm 0.12$ & $72.4 \pm 0.23$ & $423 \pm 0.03$ \\
CS2 & $51.59 \pm 0.16$ & $86.95 \pm 0.36$ & $401 \pm 0.43$ \\
CS3 & $57.98 \pm 0.47$ & $86.06 \pm 0.41$ & $494 \pm 0.52$ \\
CS4 & $41.96 \pm 0.14$ & $90 \pm 0.33$ & $485 \pm 0.16$ \\
CS5 & $59.33 \pm 0.05$ & $91.54 \pm 0.16$ & $469 \pm 0.38$ \\
CSS1 & $54.4 \pm 0.27$ & $87.19 \pm 0.36$ & $356 \pm 0.26$ \\
CSS2 & $61.29 \pm 0.62$ & $91.31 \pm 0.22$ & $407 \pm 0.14$ \\
CSS3 & $42.12 \pm 0.29$ & $80 \pm 0.43$ & $396 \pm 0.49$ \\
CSS4 & $43.47 \pm 0.32$ & $62.33 \pm 0.62$ & $404 \pm 0.04$ \\
CSS5 & $55.57 \pm 0.38$ & $81.61 \pm 0.04$ & $375 \pm 0.55$ \\
\hline
\end{tabular}

*(mean $\pm \mathrm{SD}, \mathrm{n}=3)$ 
As discussed in the selection of surfactant section, HLB value plays an important role in the formation of stable niosomes. The hydrophilic-lipophilic balance (HLB) system, which is a measure of the relative contributions of the hydrophilic and lipophilic regions of the surfactant molecules, is more commonly used as an indicator on potential niosomes formation. The HLB value of span 60 is 4.7 and HLB value of span 80 is 4.3 respectively. So considering the HLB value, Span 80 having lower HLB value compared to span 60 must be able to incorporate steroid moiety more efficiently than span 60 . But there is an exception. Sorbitan monooleate (Span 80, HLB of 4.3) cannot assemble into niosomes (on their own) due to their inadequate geometry, hence packing properties. The oleate moiety of this surfactant molecule has a double bond (with relatively high electron density) at the C9 which repels adjacent hydrocarbon chains resulting in the characteristic "kink" in the structure [42]. Vesicle size of niosomal dispersion containing span 80 was less as compared to that of span 60 (table 7). This might be due to the increase in the hydrophobicity of the surfactant from Span 60 to Span 80. The decrease in surface free energy with increasing the hydrophobicity of surfactants may be the major attribute of reduction in the vesicle size of niosomes. Since the DC of niosomes obtained by using span 80 was significantly $(\mathrm{p}<0.05)$ less due to kink in the structure as compared to span 60 , the span 60 was selected as surfactant. The results coincide with the previous study by Essa 2010 where effect of formulation and processing variables on sorbitan monopalmitate niosomes was studied.

\section{Selection of chol: surfactant ratio}

Table 8: DC, EE and vesicle size for a selection of chol: surfactant ratio

\begin{tabular}{llll}
\hline Batch code & DC (\%) & EE (\%)* & Vesicle size (nm)* \\
\hline CS6 & $64.6 \pm 0.12$ & $63.9 \pm 0.16$ & $324 \pm 0.05$ \\
CS7 & $55.8 \pm 0.35$ & $69.2 \pm 0.26$ & $357 \pm 0.15$ \\
CS8 & $66.5 \pm 0.41$ & $70.9 \pm 0.38$ & $373 \pm 0.22$ \\
CS9 & $57 \pm 0.55$ & $79.4 \pm 0.41$ & $410 \pm 0.29$ \\
CS10 & $56.3 \pm 0.26$ & $73.2 \pm 0.64$ & $428 \pm 0.45$ \\
CS11 & $42.1 \pm 0.09$ & $66.9 \pm 0.28$ & $385 \pm 0.62$ \\
CS12 & $68 \pm 0.034$ & $70.1 \pm 0.36$ & $448 \pm 0.54$ \\
CS13 & $53.5 \pm 0.49$ & $53.8 \pm 0.05$ & $424 \pm 0.32$ \\
CS14 & $68.5 \pm 0.54$ & $61.4 \pm 0.19$ & $401 \pm 0.41$ \\
CS15 & $72.4 \pm 0.06$ & $80 \pm 0.32$ & $436 \pm 0.38$ \\
CS16 & $78.1 \pm 0.42$ & $80.7 \pm 0.46$ & $417 \pm 0.61$ \\
CS17 & $86.3 \pm 0.39$ & $83.4 \pm 0.22$ & $465 \pm 0.24$ \\
\hline
\end{tabular}

$*($ mean $\pm \mathrm{SD}, \mathrm{n}=3)$

In order to find the optimum concentration ratio of chol: surfactant, different batches of niosomes were prepared (table 8) ratio value (chol: span 60) ranged from 1 to 10 . Reverse order of ratio (chol: span 60) from 2 to 3.5 was also used to prepare niosomes. The amount of chol to be added depends on the HLB value of the surfactants. As the HLB value increases above 10 , it is necessary to increase the minimum amount of chol to be added in order to compensate for the larger head groups [43]. EE decreases as the HLB value decreases from 8.6 to 1.7. It was seen that the addition of chol enables more hydrophobic surfactants to form vesicles, suppresses the tendency of the surfactant to form aggregates, and provides greater stability to the lipid bilayer by promoting the gel- liquid transition temperature of the vesicle [44]. The EE is affected by the phase transition temperature (Tc) of the surfactant. Thus Span 60 with a high Tc exhibits the highest EE. The encapsulation efficiency is improved when the chol content was increased to $50 \%$ molar ratio due to the reduction of drug permeability. A similar result was reported by Mokhtar et al. 2008 , who studied the effect of some formulation parameters such as the chol content of niosomes on flurbiprofen encapsulation and release rates of niosomes prepared from proniosomes. The optimization of the niosomal batch was not possible only on the basis of DC and EE as prolong the effect of PSP was expected (fig. 4). Hence the batch was selected on the basis of in vitro drug release.

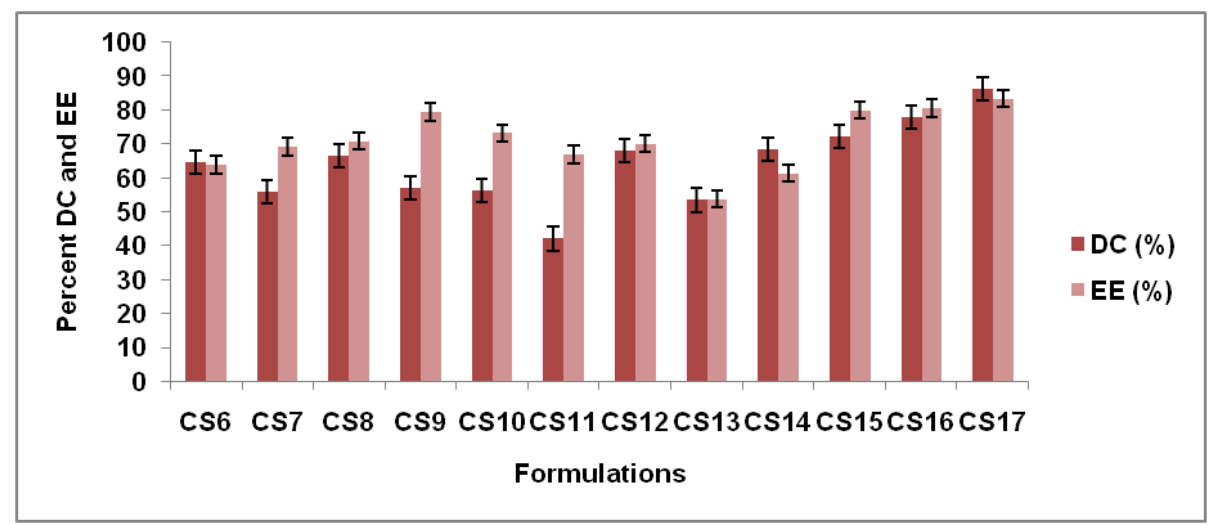

Fig. 4: Graph of DC and EE of trial batches for selection of chol: surfactant ratio data expressed mean \pm SD ( $n=3$ )

\section{In vitro drug release}

In vitro dissolution of niosomal batches was carried out by dialysis bag method. The value of $t 90$ played an important role in determining the optimized niosomal batch. Our main purpose of this study was to sustain the release of drug and hence $t 90$ was expected to be higher for the optimized batch. The batch CS17 (chol: span 60 ratio was 1) exhibited 190 of $490 \mathrm{~min}$ that is the release was 
sustained upto $8 \mathrm{~h}$ of the drug by this formulation (fig. 5 and 6). The change in chol: span60 ratio did not showed linear correlation either with DC, EE or in vitro drug release. The values differed randomly without showing any correlation. The niosomal batches CS1, CS15,CS16, CS17 all contained chol: span 60 ratio 1 i.e. both the ingredients were in equal quantities but still there $t 90$ values were variable viz $112 \mathrm{~min}, 370 \mathrm{~min}, 435 \mathrm{~min}$ and $490 \mathrm{~min}$ respectively (table 9). The difference in these batches was the change in concentration with respect to the whole composition. The amount of surfactant used in CS1 was ten times lesser than that used in CS17. Hence the value of t90 was shifted from 112 to 490 min. Surfactant concentrations were within the limits in accordance with safety guidelines where the concentration of surfactant does not exceed by $1-2.5 \% \mathrm{w} / \mathrm{w}$. In batch CS17 the amount of span is $1 \% \mathrm{w} / \mathrm{v}$. The primary function of surfactant is to improve the solubility of substance but PSP being water soluble, this function need not has to be achieved. The surfactants in higher concentrations act as sustained release polymers which cause the drug to release at the controlled rate. This was in agreement with findings of other studies like Tabbakhian M et. al 2006;Das k et. al 2011;Azeem A et. al 2008 indicating a more sustained drug permeation and possibly a greater drug deposition and increased drug release where drug containing vesicular systems used, as compared to a pure drug solution.

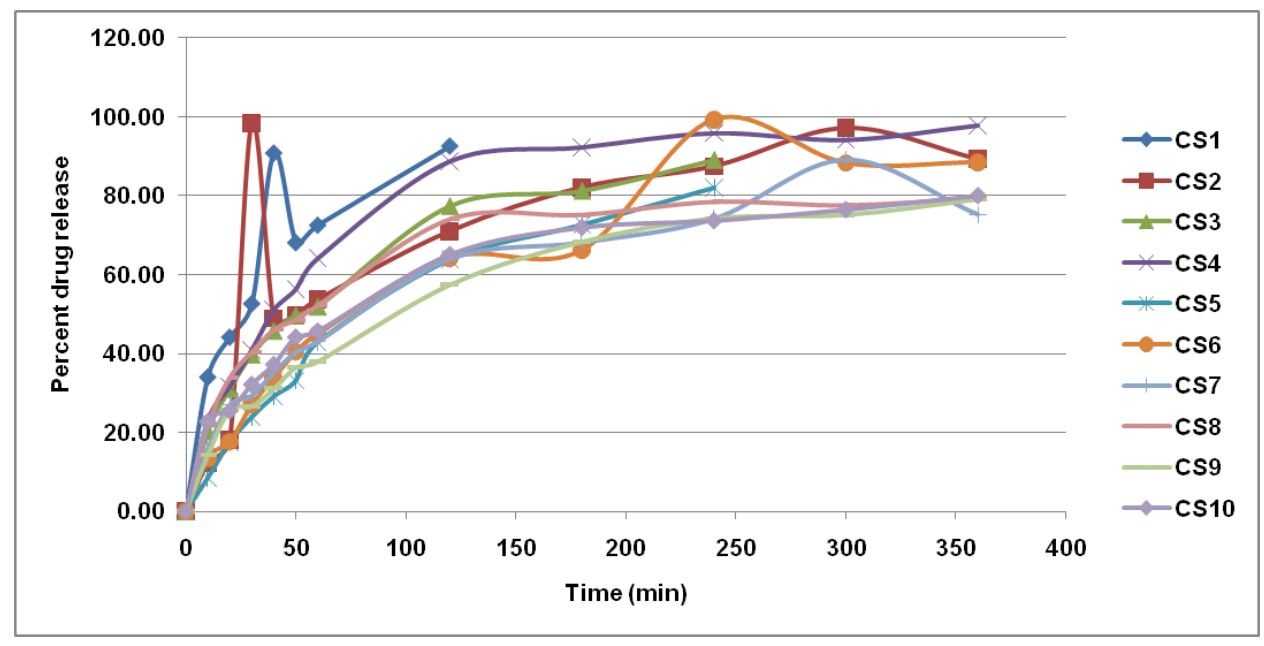

Fig. 5: Dissolution drug profile of batches CS1 to CS10data expressed mean $\pm \operatorname{SD}(n=3)$

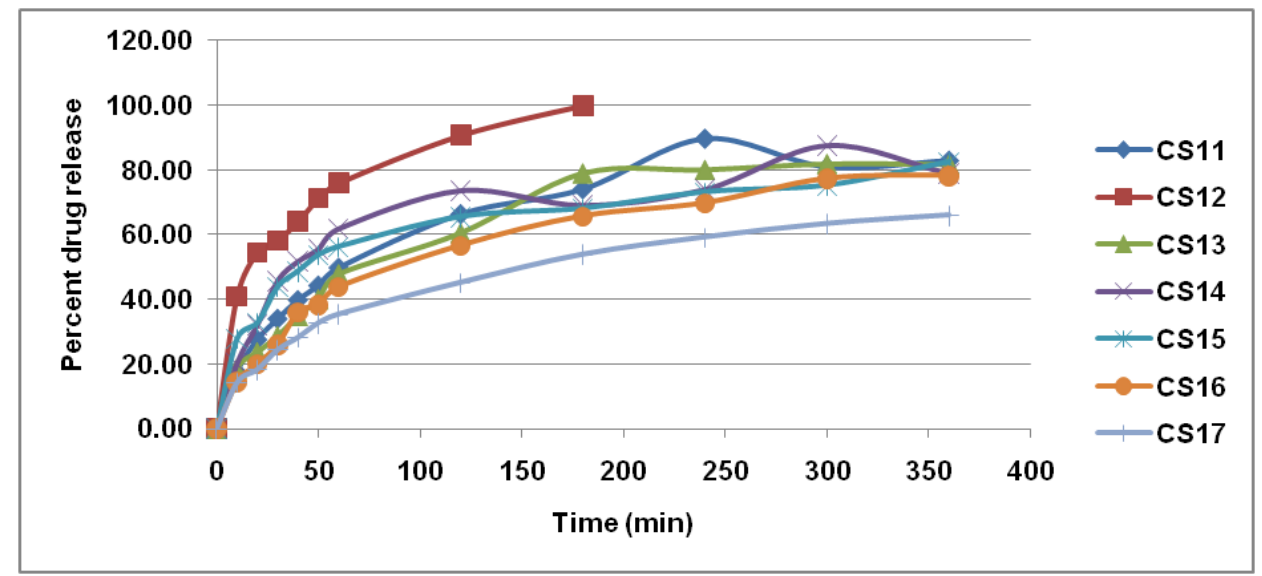

Fig. 6: Dissolution drug profile of batches CS11 to CS17data expressed mean $\pm \operatorname{SD}(n=3)$

\section{Release kinetics of drug}

The kinetics of the drug release was evaluated by model fitting method using PCP Disso v3 software and the model with the highest correlation coefficient amongst them was considered to be the best model for a particular formulation.

Different $t 90$ values were observed for different batches. The batch CS17 showed (chol: span 60-1:1) maximum t90 value of 491.9 min (table 9). This indicates that $90 \%$ drug release occurred in $490 \mathrm{~min}$ thus sustaining the release to upto $8 \mathrm{~h}$. The kinetics of the drug release was evaluated by a model fitting method using PCP Disso v3 software and the model with the highest correlation coefficient amongst them was considered to be the best model. The release kinetics indicated that the optimized batch (CS17) followed Korsmeyer Peppas kinetics where $\mathrm{R}$ is $0.9935, \mathrm{n}$ is 0.4352 and $\mathrm{k}$ is
5.846. The Korsemeyer Peppas release model equation is, $\mathrm{F}=(\mathrm{M}$ $\mathrm{t} / \mathrm{M})=\mathrm{k} \mathrm{m} \mathrm{t} \mathrm{n}$ Where $\mathrm{F}=$ fraction of drug release at time $\mathrm{t}$; $\mathrm{Mt}=$ amount of drug release at time $t ; M=$ total amount of drug in dosage form; $\mathrm{K}=$ constant. ' $\mathrm{n}$ ' is estimated from linear regression of log (Mt/M) vs $\log \mathrm{t}$. If $\mathrm{n}=0.45$, it indicates Fickian diffusion; $\mathrm{n}<0.45 \leq 0.89$ indicates non fickian diffusion. Nonfickian diffusion involves a combination of both diffusion and erosion controlled release rate [45].

\section{Fourier transform infrared spectroscopy (FTIR)}

FTIR spectra of pure drug, the physical mixture of niosomes, niososme pellets and niosomal in situ gel were evaluated (fig. 7-10). The FTIR study for the pure drug was carried out and the observed peaks were noted. From fig. 10, it was found that following were the peaks of the PSP present in the IR graph of the standard and this 
confirms the purity of the drug. The peaks were observed at 715.5, 892.8, 984.5, 1113.7, 1245.8, 1441.5, 1656.5, 1715.4, 2200.4, 2870.5, 2937.06 and $3327.6 \mathrm{~cm}^{-1}$ which corresponded to $=\mathrm{C}-\mathrm{H}$ out of plane bending, $\mathrm{C}-\mathrm{H}$ aromatic out of plane bending, $\mathrm{C}-\mathrm{H}$ stretching of alkyl substituted alkenes, $\mathrm{C}-\mathrm{H}$ in-plane bending, $\mathrm{C}-\mathrm{O}$ stretching, $\mathrm{C}=\mathrm{C}$ aromatic stretching, $\mathrm{C}=\mathrm{C}$ aromatic stretching, $\mathrm{C}=\mathrm{O}$ ester stretching, Weak combination and overtone of-C-H indicating mono-substitution on aromatic ring,- $\mathrm{CH}_{2}$-symmetrical stretching, $\mathrm{C}-\mathrm{H}$ aromatic stretching and $\mathrm{O}-\mathrm{H}$ (free) alcoholic stretching respectively [46]. An overlay of all the spectra confirmed that all the peaks of the drug were retained in physical mixture and formulation as in pure drug which indicates drug and excipients were found to be compatible with each other.

Table 9: Release kinetics of niosomal batches

\begin{tabular}{|c|c|c|c|c|c|c|c|c|c|}
\hline \multirow[t]{2}{*}{$\begin{array}{l}\text { Batch } \\
\text { Code }\end{array}$} & \multirow{2}{*}{$\begin{array}{l}\text { Zero order } \\
\text { model } \\
\mathbf{R} \\
\end{array}$} & \multirow{2}{*}{$\begin{array}{l}\text { First order } \\
\text { model }\end{array}$} & \multirow{2}{*}{$\begin{array}{l}\text { Higuchi/Matrix } \\
\text { model }\end{array}$} & \multirow{2}{*}{$\begin{array}{l}\text { HixsonCrowell } \\
\text { model }\end{array}$} & \multicolumn{3}{|c|}{$\begin{array}{l}\text { Korsmeyer-Peppas } \\
\text { model }\end{array}$} & \multirow[t]{2}{*}{$\begin{array}{l}\text { Best fit } \\
\text { kinetic model }\end{array}$} & \multirow{2}{*}{$\begin{array}{l}\text { t90 } \\
\text { Min } \\
\end{array}$} \\
\hline & & & & & $\mathbf{R}$ & $\mathbf{n}$ & $\mathbf{K}$ & & \\
\hline CS1 & 0.6148 & 0.9860 & 0.9877 & 0.9286 & 0.9987 & 0.4034 & 13.37 & $\mathrm{KP}$ & 112.8 \\
\hline $\mathrm{CS} 2$ & 0.6615 & 0.9251 & 0.9646 & 0.8872 & 0.9526 & 0.5329 & 4.8165 & M & 271.9 \\
\hline CS3 & 0.6229 & 0.9635 & 0.9817 & 0.9027 & 0.9820 & 0.4598 & 7.8542 & KP & 201.2 \\
\hline CS4 & 0.5982 & 0.9818 & 0.9726 & 0.9250 & 0.9832 & 0.4718 & 8.3280 & KP & 155.2 \\
\hline CS5 & 0.8932 & 0.9926 & 0.9849 & 0.9742 & 0.9866 & 0.6975 & 2.0973 & FO & 307.9 \\
\hline CS6 & 0.8892 & 0.8520 & 0.9785 & 0.9333 & 0.9867 & 0.6135 & 3.3073 & $\mathrm{KP}$ & 218.1 \\
\hline CS7 & 0.6320 & 0.8788 & 0.9653 & 0.8419 & 0.9836 & 0.4461 & 6.6215 & KP & 347.1 \\
\hline CS8 & 0.6321 & 0.7365 & 0.8837 & 0.5983 & 0.9683 & 0.3460 & 11.909 & $\mathrm{KP}$ & 345.8 \\
\hline CS9 & 0.7173 & 0.9369 & 0.9842 & 0.8888 & 0.9891 & 0.4683 & 5.5747 & $\mathrm{KP}$ & 379.7 \\
\hline CS10 & 0.4564 & 0.8718 & 0.9504 & 0.7877 & 0.9860 & 0.3827 & 9.1718 & $\mathrm{KP}$ & 390.7 \\
\hline CS11 & 0.5505 & 0.8696 & 0.9561 & 0.8192 & 0.9815 & 0.4330 & 7.6207 & $\mathrm{KP}$ & 299.5 \\
\hline CS12 & 0.2242 & 0.9414 & 0.9506 & 0.8244 & 0.9946 & 0.3199 & 19.98 & KP & 110.4 \\
\hline CS13 & 0.6615 & 0.9251 & 0.9646 & 0.8872 & 0.9526 & 0.5329 & 4.8165 & $\mathrm{KP}$ & 271.9 \\
\hline CS14 & 0.1567 & 0.7936 & 0.8777 & 0.6439 & 0.9339 & 0.3713 & 11.318 & $\mathrm{KP}$ & 266 \\
\hline CS15 & 0.4219 & 0.7193 & 0.8344 & 0.5055 & 0.9733 & 0.2875 & 15.69 & $\mathrm{KP}$ & 370.8 \\
\hline CS16 & 0.6864 & 0.9312 & 0.9800 & 0.8766 & 0.9834 & 0.4759 & 5.3902 & $\mathrm{KP}$ & 435.2 \\
\hline CS17 & 0.6671 & 0.8889 & 0.9826 & 0.8347 & 0.9935 & 0.4352 & 5.846 & KP & 491.9 \\
\hline
\end{tabular}

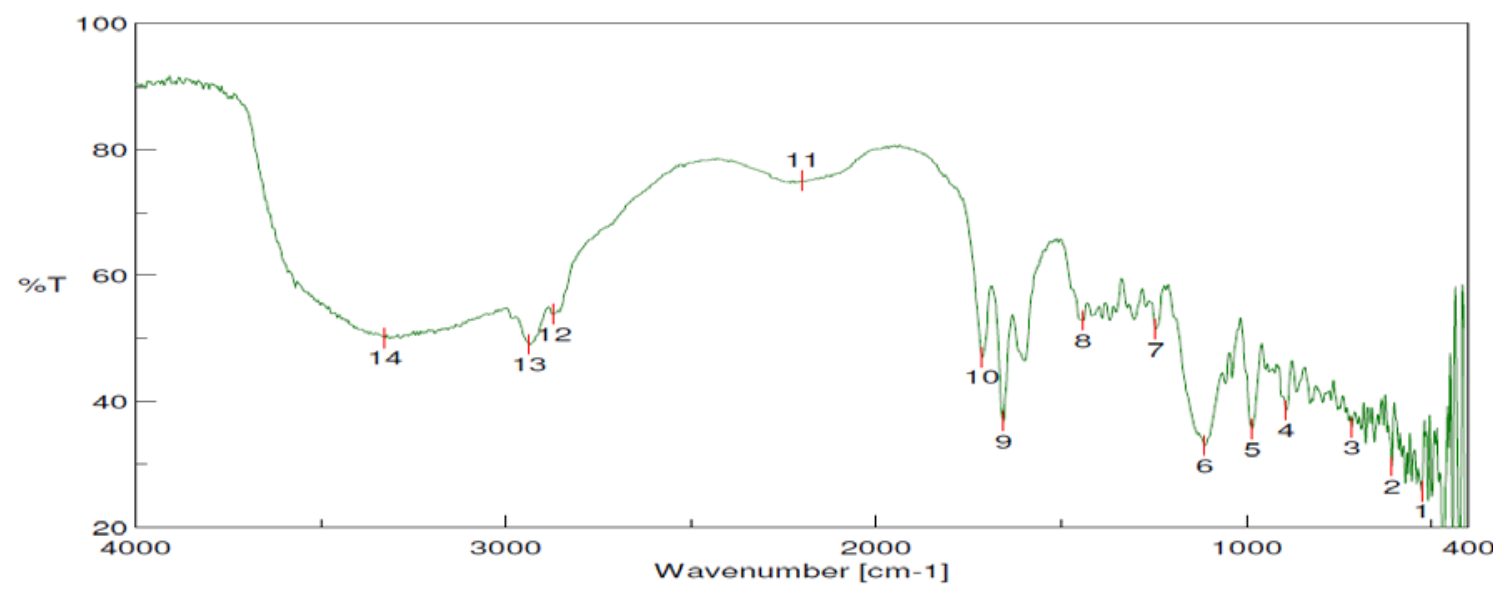

Fig. 7: FTIR spectra of PSP

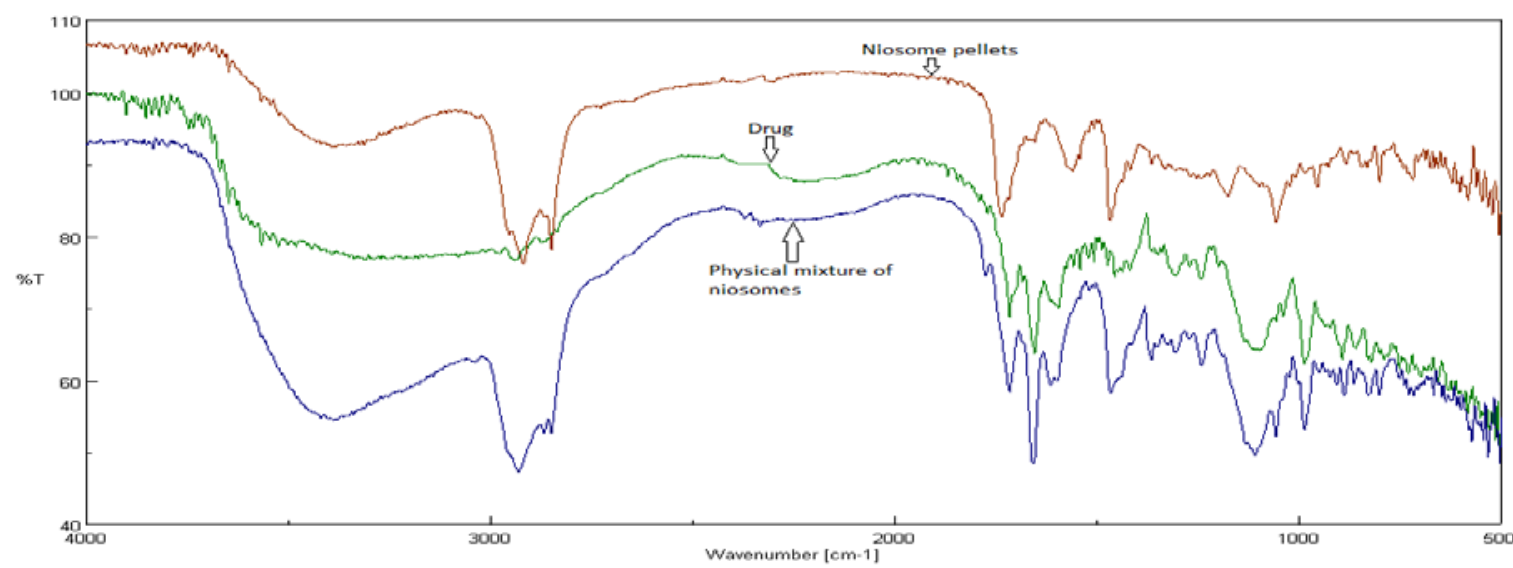

Fig. 8: Overlay of drug, physical mixture of niosomes and noisome pellets 


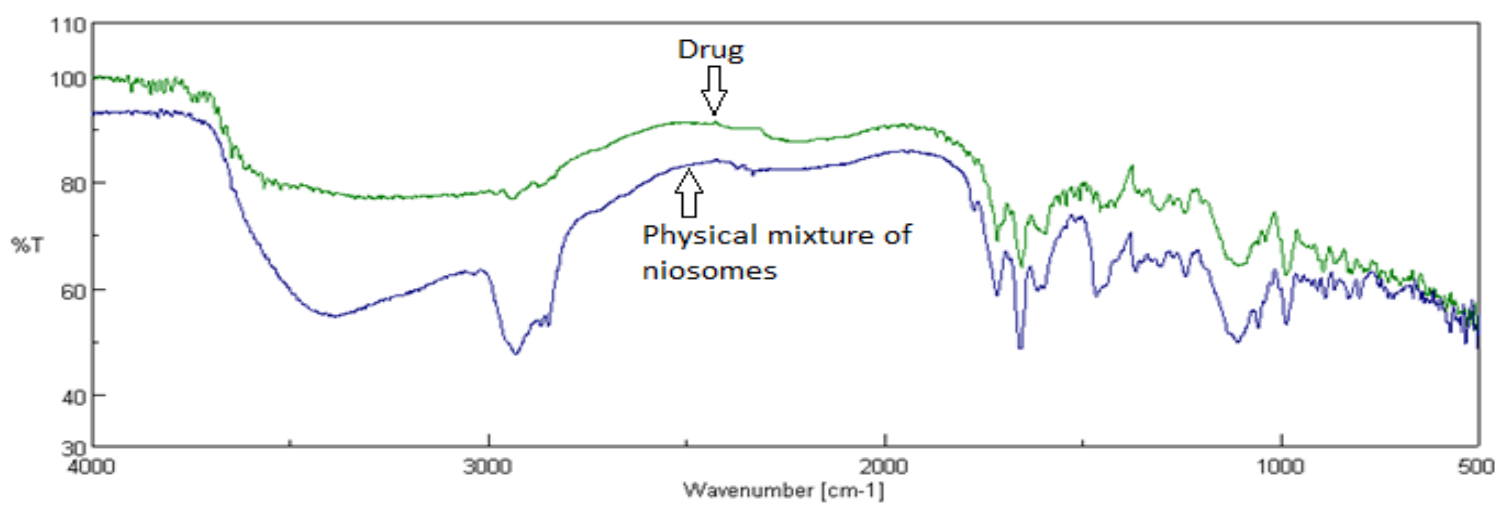

Fig. 9: Overlay of drug and physical mixture

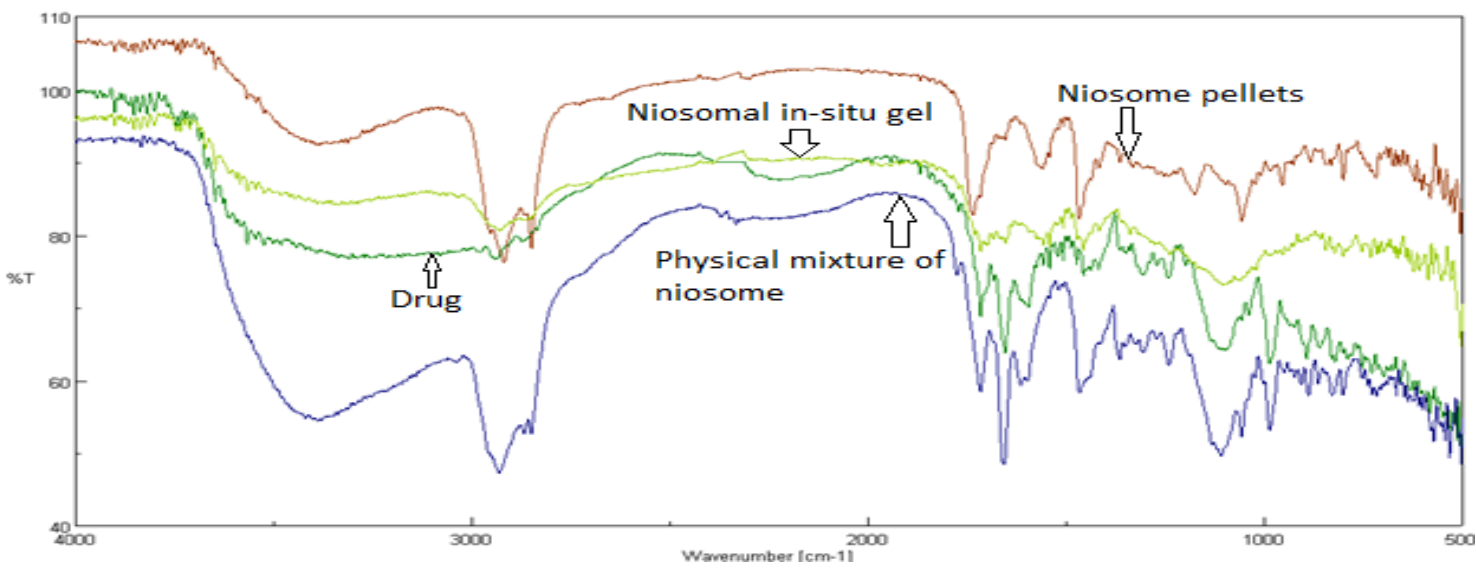

Fig. 10: Overlay of drug, physical mixture of niosomes, niosome pellets and niosomal in-situ gel

DSC

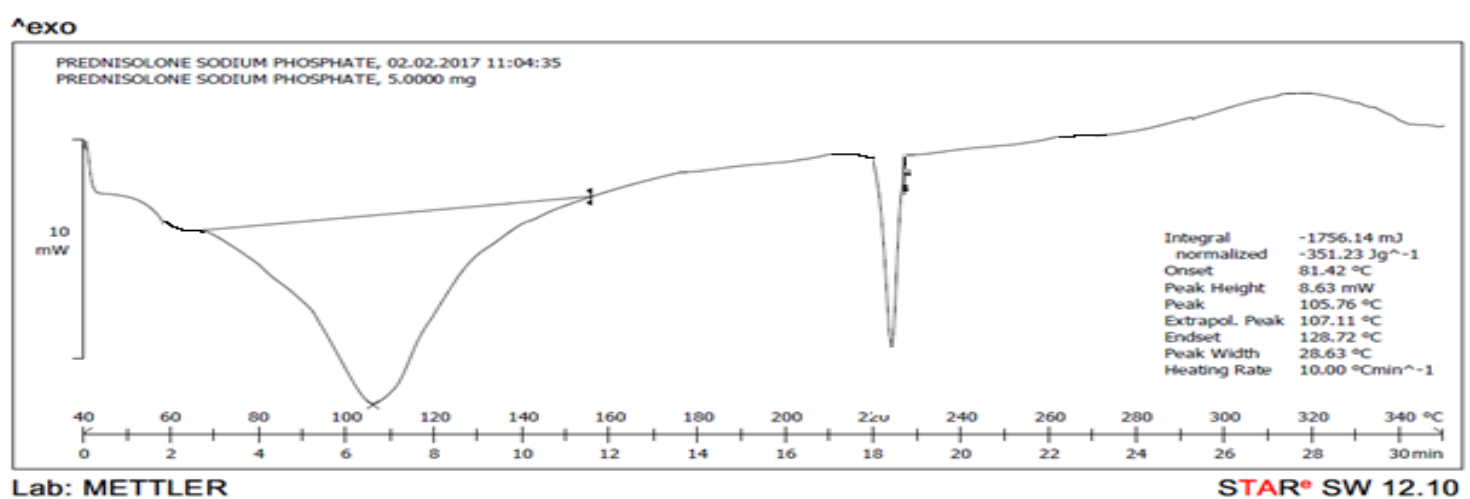

Fig. 11: DSC spectra of PSP

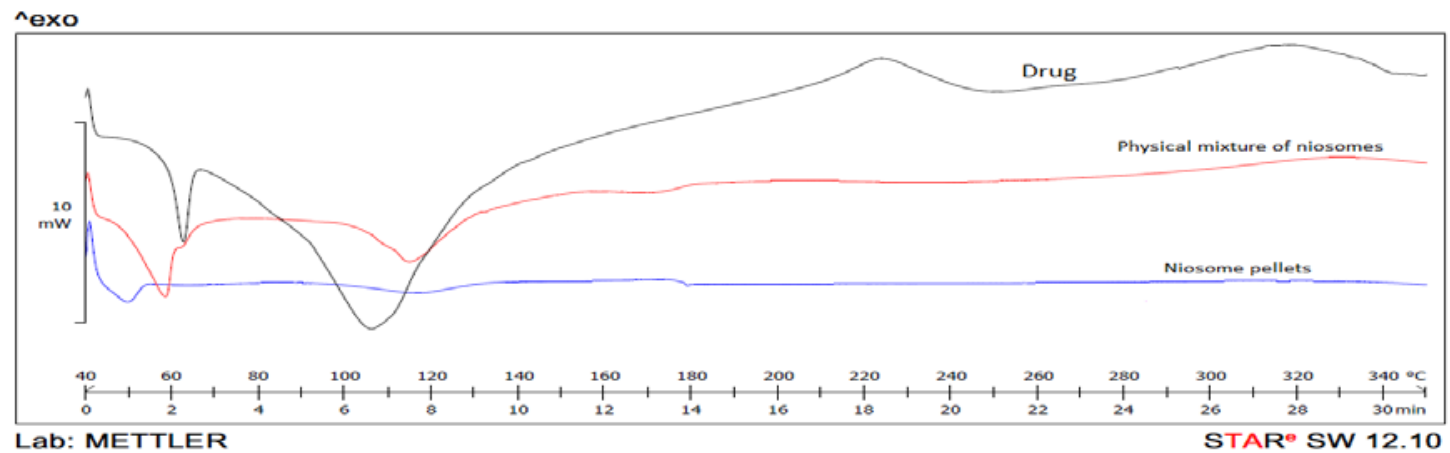

Fig. 12: Overlay of drug, the physical mixture of niosomes, and noisome pellets 


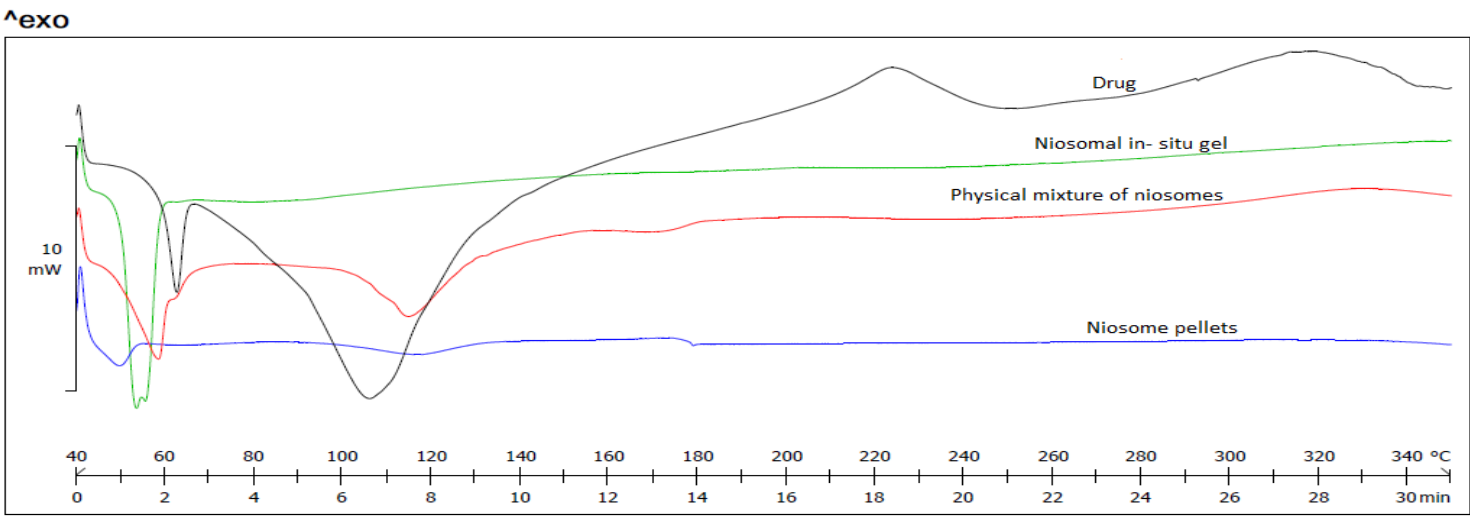

Lab: METTLER

STAR $^{\mathrm{e}} \mathrm{SW} 12.10$

Fig. 13: Overlay of drug, physical mixture of niosomes, niosome pellets and niosomal in-situ gel

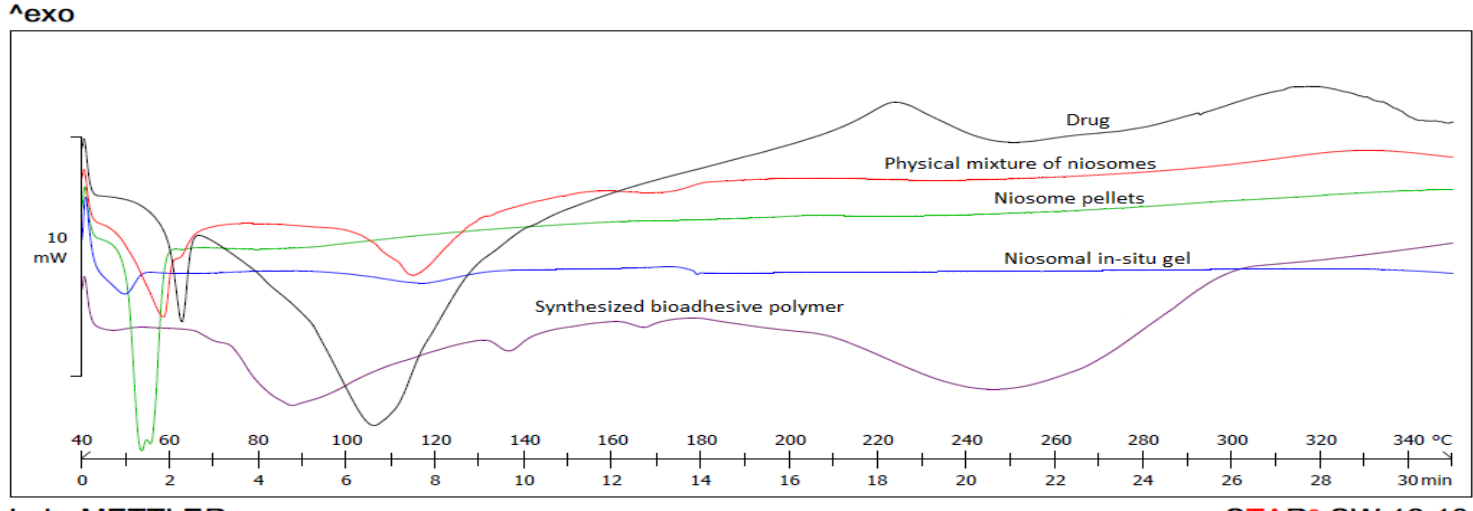

Lab: METTLER

STAR $^{\mathrm{S}}$ SW 12.10

Fig. 14: Overlay of drug, physical mixture of niosomes, niosome pellets, niosomal in-situ gel and synthesized bioadhesive polymer

DSC of the drug was performed to evaluate the thermal profile of the drug (fig. 11). The onset of the peak observed at $80^{\circ} \mathrm{C}$ represented the peak of evaporation of water molecules due to heat. A sharp endothermic peak was observed at $220{ }^{\circ} \mathrm{C}$ indicating the melting point of PSP (reported value $216{ }^{\circ} \mathrm{C}$ ). PSP crystals exhibit an endothermic peak at $320^{\circ} \mathrm{C}$ due to decomposition of PSP. The DSC thermograms of pure drug, physical mixture of niosomes, niososme pellets and niosomal in situ gel along with synthesized polymer were obtained (fig. 12,13 and 14). The peaks observed between 50 $60{ }^{\circ} \mathrm{C}$ indicated melting points of maximum excipients used in the formulation like span 60, P407 and P188 [47,48]. The cholesterol has the melting point of $148{ }^{\circ} \mathrm{C}$ which was shifted to $120{ }^{\circ} \mathrm{C}$ due to evaporation of water absorbed by the poloxamer during formulation of in situ gel. The broad peak observed at $240{ }^{\circ} \mathrm{C}$ indicates the melting point of synthesized bioadhesive polymer and drug. The absence of PSP peak on this thermogram has been taken to represent the only evidence of PSP amorphization. The physical state of the drug inside the carrier system is important because it can affect the in vitro and in vivo drug release [49]. The PSP peak was absent in the thermogram of niosomes. This situation shows that PSP was in amorphous structure and molecularly dispersed in niosomes as emphasized by Dong Y et al.2005. The amorphous PSP may be favorable due to the enhanced solubility of active agent [50].

It was stated by Nasr et al. 2008 that absence of drug's crystalline melting peak after niosomal encapsulation shows the high interaction between drug and surfactant bilayers of niosomes. This also explains the high entrapment of PSP into niosomes. In accordance with this, the entrapment of an active agent in niosomes was high in prepared formulations.

\section{Optical microscopy}

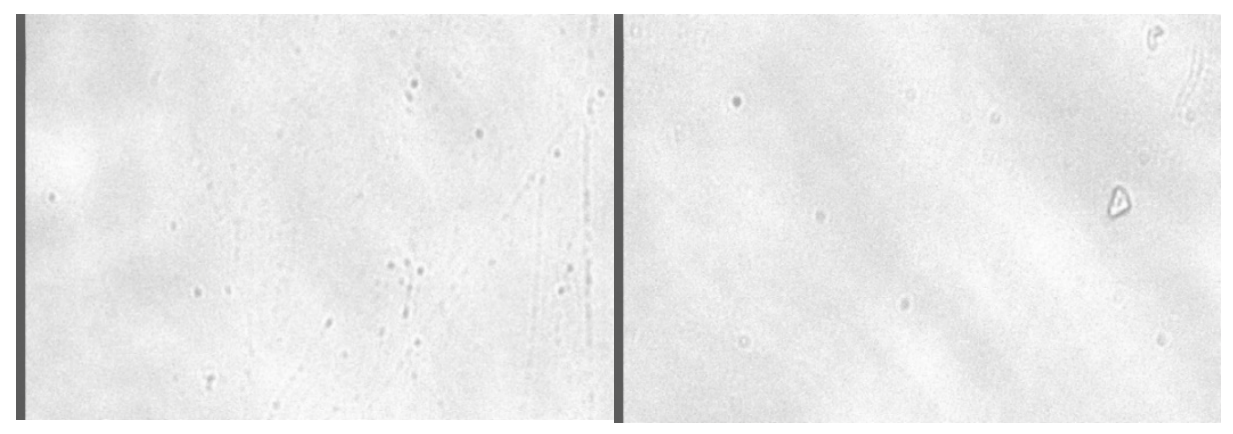

Fig. 15: Optical microscopic image of niosomes 
The niosomes were observed under the digital motic microscope (fig. 15). Vesicle size of niosomes was found to be in $0.2-0.5 \mu \mathrm{m}$ range. The vesicles were circular in shape with uniform vesicle size distribution.

\section{Vesicle size distribution}

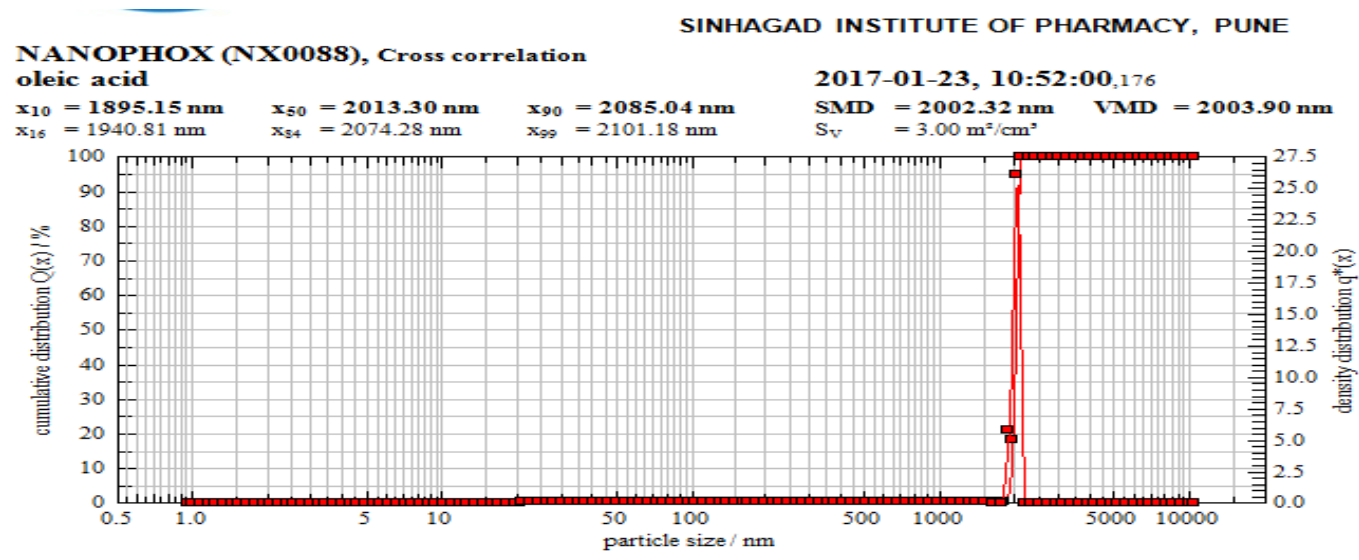

Fig. 16: Vesicle size distribution of pure drug

Vesicle size of pure drug and vesicle size of niosomal dispersion was measured by Nanophox NX0088 (fig. 16 and 17). Vesicle size of the pure drug was found to be $2002 \mathrm{~nm}$ which was reduced to $465 \mathrm{~nm}$ for niosomal dispersion. Thus the particle size was reduced by 4 times making the formulation feasible for ocular use to enhance their penetration through different biological barriers of the eye. According to previous studies of ophthalmological applications, the size of complex drug particles should be less than $10 \mu \mathrm{m}$ to avoid a foreign body sensation after administration [51]. Especially for ocular drug delivery, larger sized particles $(>1 \mu \mathrm{m})$ may potentially cause ocular irritation [52]. In the ophthalmic field, particles of size range 10 to 1000 $\mathrm{nm}$ allow for the improved topical passage of large molecules through the barriers of the ocular system [53]. Based on these results, delivery of ocular therapeutics via niosomes can be used to reduce the sensation and irritation of the eye.

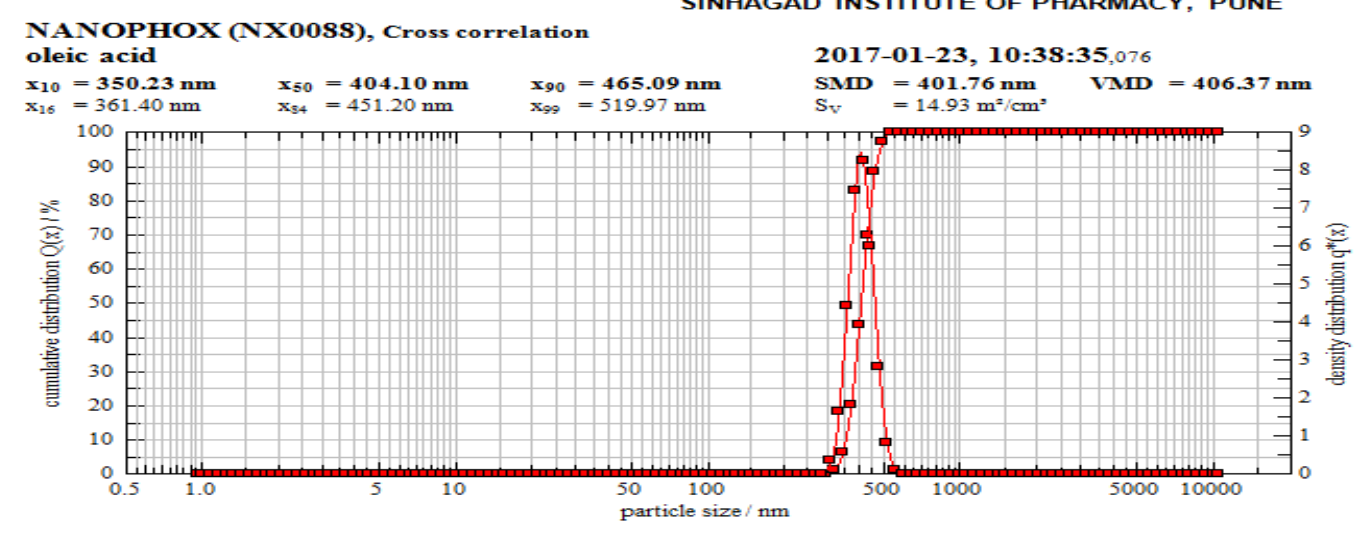

Fig. 17: Vesicle size distribution of niosomal dispersion

\section{Zeta potential determination}

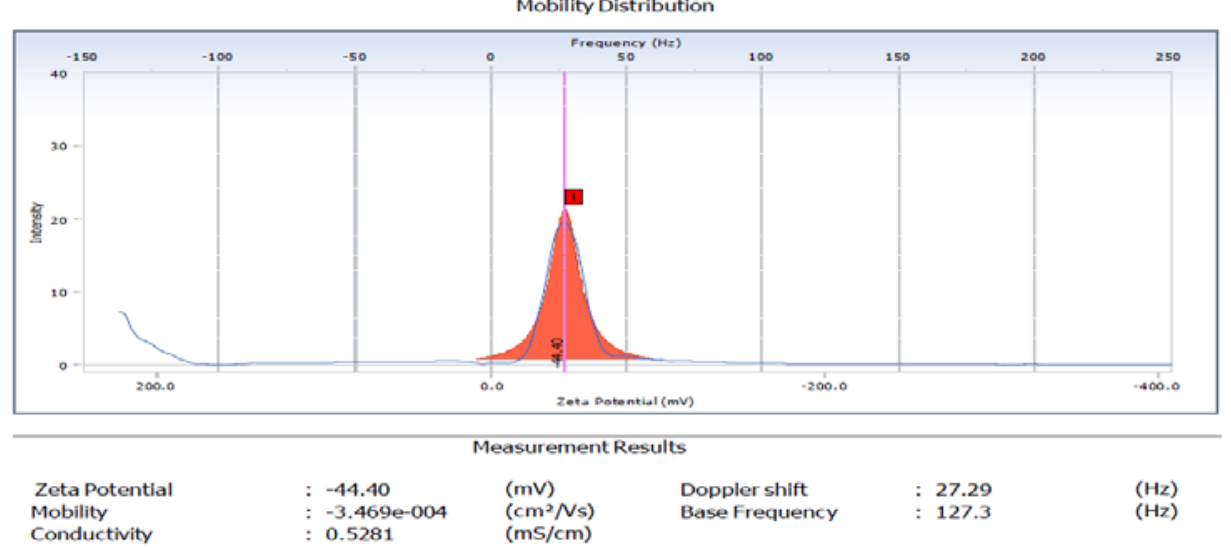

Fig. 18: Zeta potential of niosomal formulation 
The zeta potential for niosomal formulation was measured by zetasizer. It has long been recognized that the zeta potential is a very good index of the magnitude of the interaction between colloidal particles. Dissociation of acidic groups on the surface of a particle will give rise to a negatively charged surface. The magnitude of the surface charge depends on the acidic or basic strength of the surface groups and on the $\mathrm{pH}$ of the solution. The zeta potential of the noisome under study was found to be- $44 \mathrm{mV}$ (fig. 18). The negative charge is contributed by the negatively charged sulfonate groups present in span 60 . The presence of a net charge, whether negative or positive, can increase water uptake within the double layer. It implies that equal molarity of nonionic surfactant and chol can make the membrane compact and well organized [54]. The magnitude of the zeta potential gives an indication of the potential stability of the colloidal system. If all the particles in suspension have a large negative or positive zeta potential, then they will tend to repel each other and there will be no tendency for the particles to come together. However, if the particles have low zeta potential values then there will be no force to prevent the particles from coming together and flocculating. The general dividing line between stable and unstable dispersions is generally taken at either +30 or $-30 \mathrm{mV}$. Particles with zeta potentials more positive than $+30 \mathrm{mV}$ or more negative than $-30 \mathrm{mV}$ are normally considered stable. Thus it indicates that the formulation is stable and particle size will not increase due to aggregation or coagulation even after the formulation is kept for a long period of time.

PDI

Table 10: PDI of pure drug and niosomal formulation

\begin{tabular}{lll}
\hline S. No. & Sample name & PDI* $^{*}$ \\
\hline 1. & Pure drug & $0.095 \pm 0.003$ \\
2. & Niosomal Formulation & $0.284 \pm 0.026$ \\
\hline
\end{tabular}

*(mean $\pm \mathrm{SD}, \mathrm{n}=3)$

PDI values were calculated from vesicle size distribution data. The PDI value of formulation was found to be in the 0.284 which was found to be in the standard range i.e. less than 1 indicating that the formulation is monodisperse (table 10). The quality and uniformity of the dispersed systems are expressed with the PDI values. The values less than 0.7 are considered as suitable measurements. The low PDI values demonstrated the narrow size distribution and uniformity of the niosomal suspension [55]. Homogeneity of niosomal dispersions was indicated by the PDI values.

\section{TEM analysis}

Morphological characteristics of niosomal formulations were further confirmed by TEM analysis. TEM photomicrograph of (CS17) niosomal formulation at 40,000x and 45,000x (fig. 19) magnification revealed the spherical shape and morphology of the niosomes. Further, it was observed from the TEM images that niosomes are with hollow vesicular structure. The vesicle size $(432 \mathrm{~nm})$ observed in TEM was found to coincide with the value obtained by vesicle size determination thus confirming the size of vesicles to be in the colloidal range.

\section{In situ gel preparation}

Preliminary batches were prepared by varying the concentrations of P407 and P188 indifferent ratios and evaluated for gelation temperature (table 11). The concentration of $\mathrm{P} 407$ was varied from 10 to $23 \% \mathrm{w} / \mathrm{v}$ whereas the concentration of P188 was varied from $10-30 \% \mathrm{w} / \mathrm{v}$. While defining the ratios, care was taken that the total poloxamer concentration should not exceed $40 \% \mathrm{w} / \mathrm{v}$. The formulations containing only P407 showed higher sol-gel transition temperatures than the gel bases containing P188 in combination with it. The sol-gel transition temperature increased when the P407 concentration was decreased. This observation was in accordance with the data available in the literature [56]. When the mixtures were compared according to the ratio of $\mathrm{P} 407 / \mathrm{P} 188$, it was observed that the $\mathrm{w} / \mathrm{w}$ percent ratio of $\mathrm{P} 407 / \mathrm{P} 188$ was important to reach the desirable gelation temperature and the result was compatible with the literature $[57,58]$.

It was found that with the increase in the concentration of P188, the gelation temperature decreased significantly $(p<0.05)$ and found to be equivalent to the physiological temperature that is $36-37^{\circ} \mathrm{C}$. Gelation temperatures for P188 and P407 gels were observed for the different concentration range of polymer, and it was found that the gelation temperature of formulation decreased with increasing concentration of polymer. As the concentration of polymer increases, the gel structure becomes more closely packed with the arrangement in the lattice pattern [59].
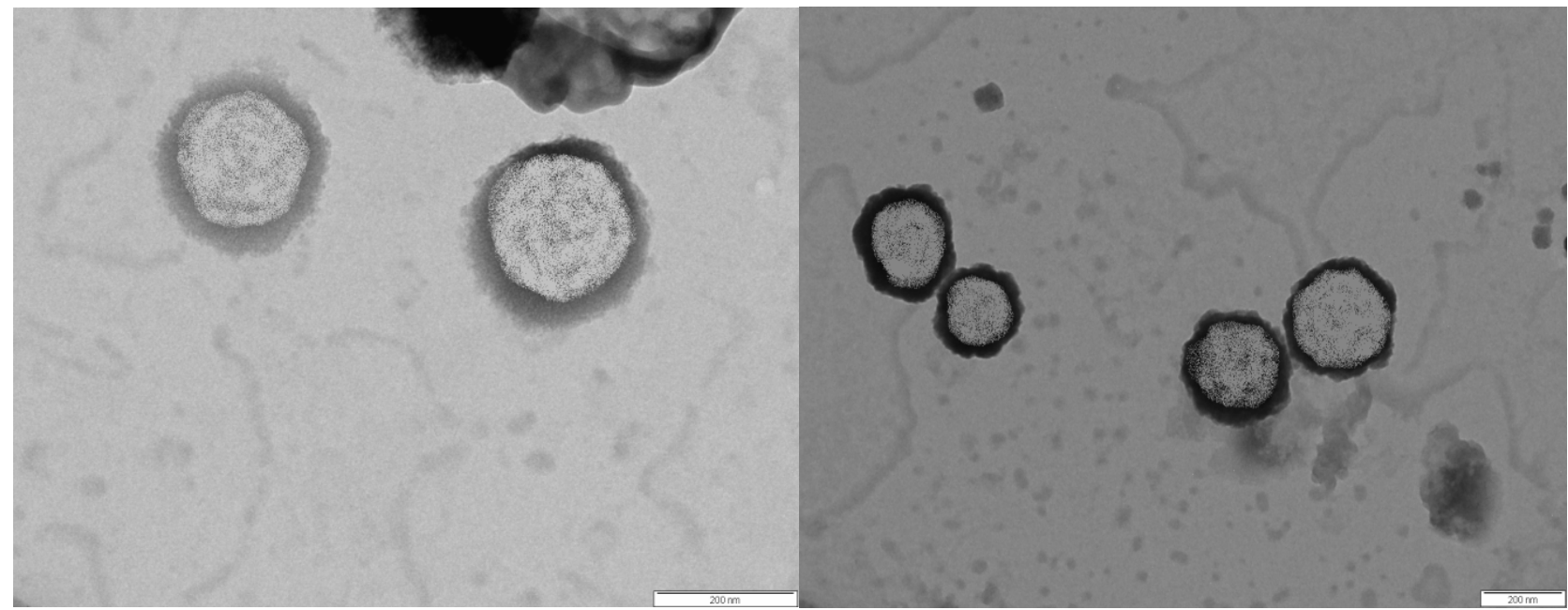

Fig. 19: TEM images of optimized niosomal batch (CS17) 
Evaluation of in situ gel

Preliminary batches of in situ gel

Table 11: Formulation batches of in situ gel along with gelation time, gel capacity and gel temperature

\begin{tabular}{|c|c|c|c|c|c|}
\hline Batch code & $\begin{array}{l}\text { P407 } \\
(\% w / v)\end{array}$ & P188 (\%w/v) & Gelation temperature $\left({ }^{\circ} \mathrm{C}\right)$ & Gel capacity* & Gelation time (min) \\
\hline G1 & 20 & - & $>60$ & - & - \\
\hline G2 & 18 & - & $>60$ & - & - \\
\hline G3 & 16 & - & $>60$ & - & - \\
\hline G4 & 21 & - & $>60$ & - & - \\
\hline G5 & 22 & - & $>60$ & - & - \\
\hline G6 & 23 & - & $>60$ & - & - \\
\hline G7 & 20 & 14 & $>60$ & - & - \\
\hline G8 & 20 & 15 & $>60$ & - & - \\
\hline G9 & 20 & 16 & $>60$ & - & - \\
\hline G10 & 23 & 14 & $>60$ & - & - \\
\hline G11 & 22 & 15 & $>60$ & - & - \\
\hline G12 & 21 & 16 & $>60$ & - & - \\
\hline G13 & 15 & 15 & $>60$ & - & - \\
\hline G14 & 20 & 10 & $>56$ & - & - \\
\hline G15 & 17 & 17 & $>60$ & - & - \\
\hline G16 & 10 & 11 & $>57$ & + & - \\
\hline G17 & 11 & 10 & $>57$ & + & - \\
\hline G18 & 11 & 11 & $>57$ & + & - \\
\hline G19 & 10 & 12 & $>52$ & - & - \\
\hline G20 & 12 & 20 & $>52$ & - & - \\
\hline G21 & 12 & 12 & $>52$ & - & - \\
\hline G22 & 20 & 13 & $48-52$ & - & - \\
\hline G23 & 13 & 20 & $48-52$ & - & - \\
\hline G24 & 13 & 13 & $48-52$ & - & - \\
\hline G25 & 10 & 15 & 43 & + & - \\
\hline G26 & 15 & 20 & 43 & - & - \\
\hline G27 & 15 & 15 & 42 & - & $<1$ \\
\hline G28 & 10 & 16 & 43 & + & $<1$ \\
\hline G29 & 17 & 10 & 42 & + & $<1$ \\
\hline G30 & 17 & 17 & 43 & ++ & $<1$ \\
\hline G31 & 10 & 18 & 42 & + & $<1$ \\
\hline G32 & 18 & 20 & 42 & ++ & $<1$ \\
\hline G33 & 20 & 18 & 40 & ++ & $<1$ \\
\hline G34 & 10 & 25 & $37-38$ & +++ & $<1$ \\
\hline G35 & 10 & 27 & $37-38$ & +++ & $<1$ \\
\hline G36 & 10 & 30 & $36-37$ & +++ & $<1$ \\
\hline
\end{tabular}

*(-): The solutions which did not undergo a phase transition at all. (+): The solutions which exhibited a phase transition only after 60 s. and the formed gels which collapsed within 1-2 h. (++): The solutions which formed the gels after 60 s. however, the gels formed did not remain stable for more than $3 \mathrm{~h} .(+++)$ : The solutions which exhibited phase transition within $60 \mathrm{~s}$ and the gels so formed remained stable for more than 7-8 $\mathrm{h}$.

\section{Evaluation parameters of in situ gel}

Table 12: Evaluation results of shortlisted formulations

\begin{tabular}{|c|c|c|c|}
\hline Formulations & G34 (A) & G35 (B) & G36 (C) \\
\hline Appearance & Translucent & Translucent & Translucent \\
\hline $\mathrm{pH}^{*}$ & $6.8 \pm 0.1$ & $6.5 \pm 0.1$ & $6.7 \pm 0.1$ \\
\hline Drug content $(\%)^{*}$ & $88.45 \pm 0.37$ & $91.37 \pm 0.26$ & $86.13 \pm 0.15$ \\
\hline Gelation temperature $\left({ }^{\circ} \mathrm{C}\right)^{*}$ & $37.7 \pm 0.5$ & $37.2 \pm 0.5$ & $36.9 \pm 0.5$ \\
\hline Gel strength $(\mathrm{s})^{*}$ & $29 \pm 0.36$ & $32 \pm 0.42$ & $35 \pm 0.18$ \\
\hline Gelation time (min) & $<1$ & $<1$ & $<1$ \\
\hline Mucoadhesive strength (dynes $\left./ \mathrm{cm}^{2}\right)^{*}$ & $1837 \pm 0.35$ & $2043 \pm 0.26$ & $2465 \pm 0.14$ \\
\hline Spreadability $(\mathrm{cm})^{*}$ & $2.3 \pm 0.33$ & $2.1 \pm 0.52$ & $1.8 \pm 0.08$ \\
\hline
\end{tabular}

$*($ mean $\pm \mathrm{SD}, \mathrm{n}=3)$

The appearance of the formulation was translucent since niosomal pellets equivalent to drug dose were introduced into the gel formulation (table 12). The $\mathrm{pH}$ of the solution was found to be in the range of 6.5 to 6.8 since the $\mathrm{pH}$ of the formulation was maintained by addition of $0.1 \mathrm{M} \mathrm{NaOH}$. The effect of polymer concentration on drug content was negligible because the drug was incorporated into niosomes and the drug was not directly dissolved into the gel formulation. Thus, DC was affected by niosomal formulation parameters and not by gel formulation parameters. With the increase in the concentration of P188, the gelation temperature was decreased and thus the optimum temperature of $37.2 \pm 0.2{ }^{0} \mathrm{C}$ was obtained. Gel strength is the indication of the viscosity of the gel formulation. It was observed that with the increase in polymer concentration, gel strength was also increased. The mucoadhesive 
strength limits the total clearance of drug from the ocular surface. Defining the mucoadhesive characteristics is of great importance when prolonged residence time and a decreased leakage of the formulation with the mucosal secretion are required [56]. The bioadhesive strength was not significantly affected by polymer concentration because the amount of addition of synthesized bioadhesive polymer was constant in all the three formulations. The bioadhesive strength of formulation was increased with increase in the concentration of polymer forming in situ gel formulation. In the literature, it was shown that P407 increased the mucoadhesive force of the formulation. It was also presented that the formulation prepared with the mixture of $\mathrm{P} 407 / \mathrm{P} 188$ increased the bioavailability by preventing the migration of the formulation from the mucosal tissue [58]. This was in accordance with our data and the studies on the mucoadhesive property of poloxamers. The spreadability of the gel formulation was measured by texture analyzer. It was found that with the increase in polymer concentrations, the spreadability decreased significantly $(p<0.05)$ due to the increase in viscosity of the formulation. It has been observed that increasing the concentration of any of the gelling agents was always associated with a decrease in the spreadability
[60]. One of the criteria for a gel to meet the ideal quality is that it should possess good spreadability. It is the term expressed to denote the extent of area, to which gel readily spreads on application site. Lesser the time is taken for separation of two slides, better the spreadability. The gelling capacity of the formulation was measured on the basis of gelation time and time for which the gel remains to hold its solid state. It was observed that with significant $(\mathrm{p}<0.05)$ increase in P188 concentration (above 20\% w/v), the gelling capacity improved thus forming within $60 \mathrm{~s}$ and holding its state for more than 7-8 $\mathrm{h}$.

\section{Viscosity measurements}

The viscosity of the optimized formulation was measured at a different temperature from $25{ }^{\circ} \mathrm{C}$ to $40{ }^{\circ} \mathrm{C}$ (fig. 20). It was observed that the viscosity of gel was suddenly increased between temperature $35-37^{\circ} \mathrm{C}$ which indicated sol to gel transformation. The viscosity of gel formulation was found to be in the range of 800-900 cps below $35{ }^{\circ} \mathrm{C}$ which increased to about $4000-5000$ cps above 35 ${ }^{0} \mathrm{C}$ indicating gelation temperatures. The increase in the concentration of P188 caused the decrease in the gelation temperature.

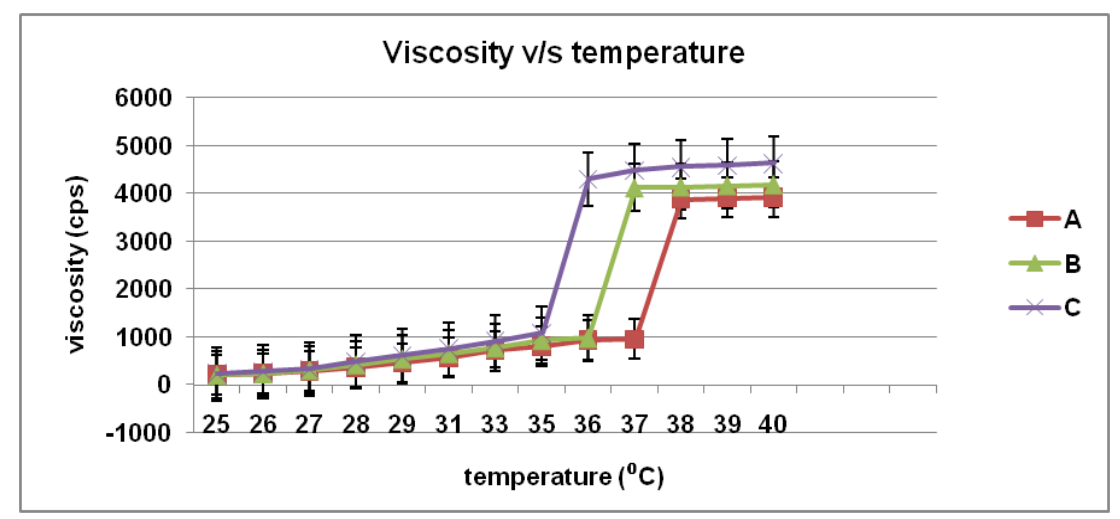

Fig. 20: Effect of temperature on viscosity of in situ gel data expressed mean $\pm S D(n=3)$

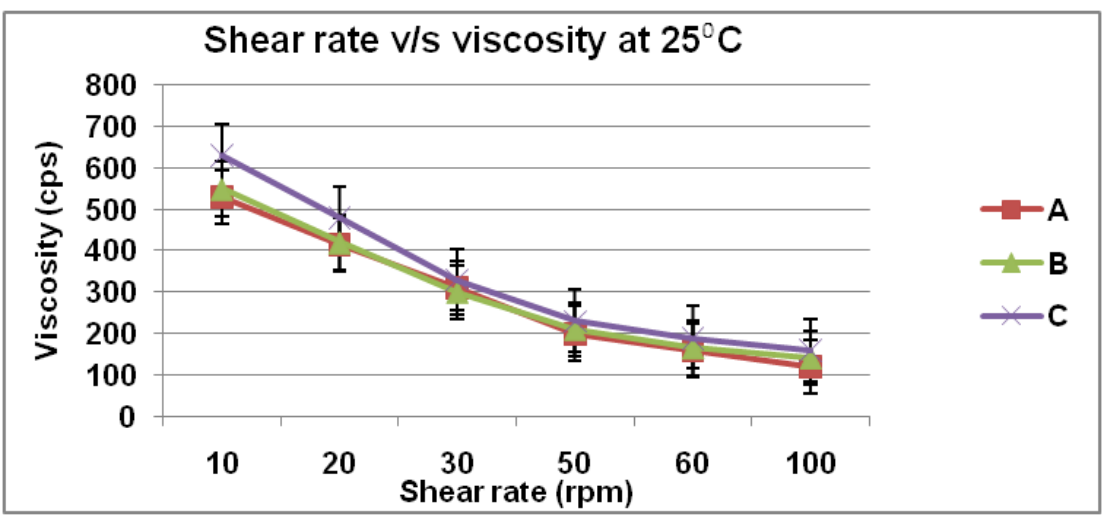

Fig. 21: Comparison of viscosity change with change in shear rate at $25^{\circ} \mathrm{C}$ for different formulations data expressed mean $\pm \mathrm{SD}(\mathrm{n}=3$ )

All the formulations showed pseudoplastic rheological flow after studying at various temperatures, as evidenced by shear thinning and increase in shear stress with increased angular velocity. It was found that the rheological parameter was directly dependent on polymer concentration of formulation. At $25{ }^{\circ} \mathrm{C}$, all formulations were having low viscosity (fig. 21 ) and at $37{ }^{\circ} \mathrm{C}$, the formulations showed high viscosity (fig. 22). This indicates conversion of these formulations from sol to gel. It was also observed that viscosity of all the formulations was decreasing with the increase in shear rate. The non-newtonian formulations with pseudoplastic properties can acquire a viscosity decrease with increasing shear rate, creating blinking and ocular movement. Pseudoplasticity is thus interesting because it offers significantly less resistance to blinking and shows much greater acceptance than viscous newtonian formulations [61].

\section{In vitro drug diffusion study}

The in vitro drug release profile of gel formulations was calculated by PCP disso software where the percent drug release along with dissolution kinetics and best fit model was found out. T90 value was found out using this PCP disso V3 software and comparison was done on its basis (fig. 23). The apparent diffusion coefficient values are given in table 12 . It was observed that the diffusion coefficient for optimized formulation (1.998 $\left.\times 10^{-5} \mathrm{cms}^{-1}\right)$ was higher as compared to the pure drug $\left(0.710 \times 10^{-5} \mathrm{cms}^{-1}\right)$ and marketed 
formulation $\left(0.865 \times 10^{-5} \mathrm{cms}^{-1}\right)$ thus proving increased permeability of drug through the membrane (table 13). These results can be attributed to the presence of bioadhesive polymer which retains the formulation in contact with the eye for a long period of time.

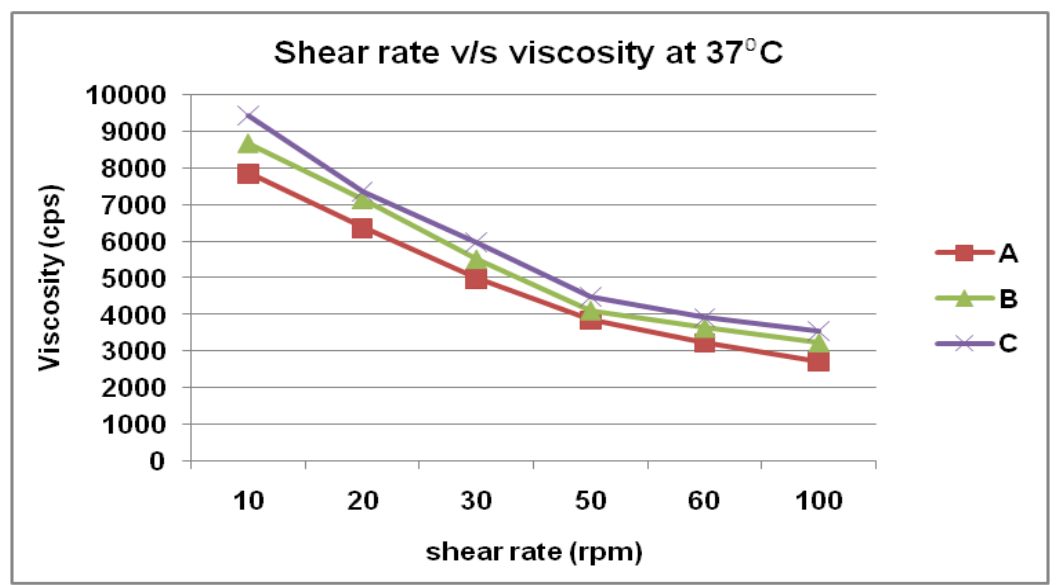

Fig. 22: Comparison of viscosity change with change in shear rate at $37^{\circ} \mathrm{C}$ for different formulations data expressed mean $\pm S D(n=3)$

The presence of polymers in in situ gel (P188 and P407) in lower concentrations acts as penetration enhancers and thus helps in penetration of PSP through the membrane. T90 value is the time at which $90 \%$ of the drug is released (table 14). A, B and C batch exhibited 90 value of $523 \mathrm{~min}$ ( $8 \mathrm{~h}$ and $43 \mathrm{~min}), 596 \mathrm{~min}(9 \mathrm{~h} 56 \mathrm{~min})$ and $555 \mathrm{~min}(9 \mathrm{~h} 15 \mathrm{~min})$ respectively. The release kinetics indicated that it followed zero order which means drug release does not depend on initial concentration.

The B batch (P407:P188-1:2.7) was found to be the optimized batch with maximum $t 90$ value thus sustaining the action for a long period of time. The marketed formulation and the pure drug showed 20$23 \%$ drug diffusion in $6 \mathrm{~h}$ whereas the drug released by niosomal formulation was found to be in the range of $45-50 \%$ in $6 \mathrm{~h}$. Thus the amount of drug diffused was increased by niosomal in situ gel formulation. O. Inal et al. 2013 observed that the presence of P188 polymer increased the release of meloxicam due to the change in the ratio of Poly Propylene oxide/Poly Ethylene Oxide (PPO/PEO) units in the polymer. Comparably shorter chain and low PPO/PEO molar ratio of hydrophilic P188 tend to disrupt the hydration shells around the hydrophobic portion of P407 molecules, which resulted as the high degree of water molecules around the PPO units. During gelation, those ordered water molecules had to be squeezed out into the bulk solution. Therefore, an increase in temperature required to promote the hydroscopic interaction between poloxamer micelles [62].

Thus, the gel prepared with P188 has more tendencies to erode. As seen in fig. 23, formulations including P407:P188 combination $(\mathrm{A}, \mathrm{B}, \mathrm{C})$ showed higher erosion profiles than the others probably due to the decrease in PPO/PEO molar ratio of polymer in the gel.

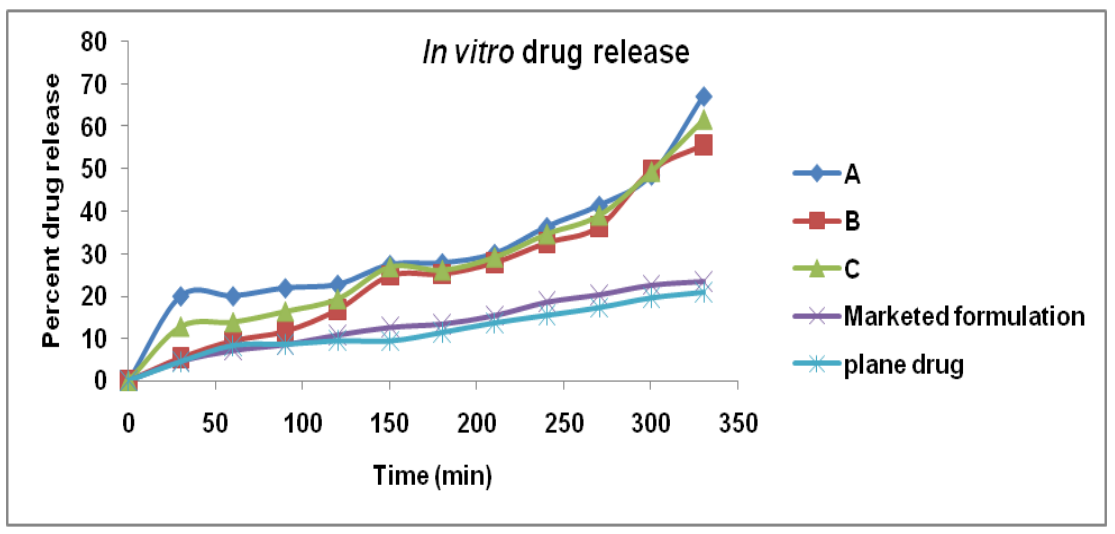

Fig. 23: In vitro drug release profile of in situ niosomal batches data expressed mean $\pm \operatorname{SD}(n=3)$

Table 13: Amount of drug released in $6 \mathrm{~h}$ and apparent diffusion coefficient of different batches

\begin{tabular}{llll}
\hline S. No. & Batch & Amount of drug diffused in 6 $\mathbf{~ h}^{*}$ & Apparent diffusion coefficient (cm s $\left.^{-1}\right)^{*}$ \\
\hline 1. & A & $48.55 \pm 0.12$ & $1.853^{*} 10^{-5}$ \\
2. & B & $49.72 \pm 0.37$ & $1.998^{*} 10^{-5}$ \\
3. & C & $49.04 \pm 0.24$ & $1.892^{*} 10^{-5}$ \\
4. & Pure drug & $19.52 \pm 0.48$ & $0.710^{*} 10^{-5}$ \\
5. & Marketed formulation & $22.64 \pm 0.59$ & $0.865^{*} 10^{-5}$ \\
\hline
\end{tabular}

$*($ mean \pm SD, $\mathrm{n}=3)$ 
Table 14: Release kinetics of in situ niosomal batches

\begin{tabular}{|c|c|c|c|c|c|c|c|c|c|}
\hline \multirow{2}{*}{$\begin{array}{l}\text { Batch } \\
\text { Code }\end{array}$} & \multirow{2}{*}{$\begin{array}{l}\text { Zero-order } \\
\text { model }\end{array}$} & \multirow{2}{*}{$\begin{array}{l}\text { First order } \\
\text { model }\end{array}$} & \multirow{2}{*}{$\begin{array}{l}\text { Higuchi/Matrix } \\
\text { model }\end{array}$} & \multirow{2}{*}{$\begin{array}{l}\text { Hixson-Crowell } \\
\text { model }\end{array}$} & \multicolumn{3}{|c|}{ Korsmeyer-Peppas model } & \multirow{2}{*}{$\begin{array}{l}\text { Best fit } \\
\text { kinetic model }\end{array}$} & \multirow{2}{*}{$\begin{array}{l}\text { t90\% } \\
\text { Min } \\
\end{array}$} \\
\hline & & & & & $\mathbf{R}$ & $\mathbf{N}$ & $\mathbf{K}$ & & \\
\hline A & 0.9146 & 0.883 & 0.892 & 0.902 & 0.8526 & 0.4819 & 2.7082 & $\mathrm{ZO}$ & 523.4 \\
\hline B & 0.9777 & 0.946 & 0.888 & 0.959 & 0.9728 & 0.9384 & 0.2028 & $\mathrm{ZO}$ & 596.1 \\
\hline $\mathrm{C}$ & 0.9631 & 0.928 & 0.904 & 0.944 & 0.9353 & 0.6425 & 1.0740 & $\mathrm{ZO}$ & 555.6 \\
\hline
\end{tabular}

Ex vivo drug release studies

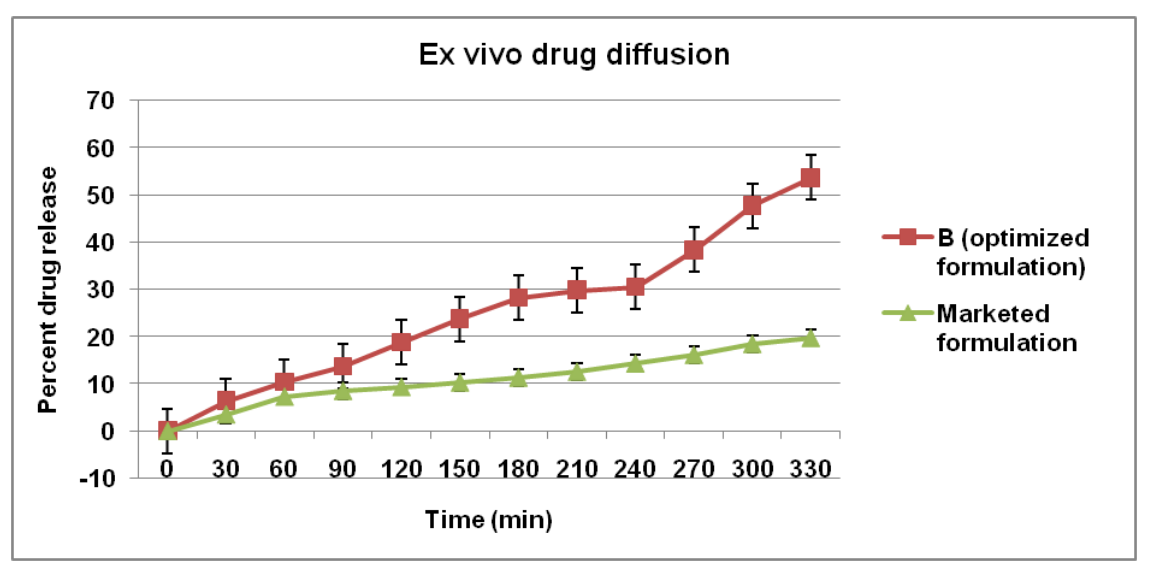

Fig. 24: Ex vivo drug diffusion of optimized formulation data expressed mean $\pm S D(n=3)$

The ex vivo drug diffusion study of optimized formulation showed that $90 \%$ of drug release was obtained in $10 \mathrm{~h}$ providing sustained effect (fig. 24). It is clear that a significantly higher amount $(p<0.05)$ of PSP permeated from the optimized formulation as compared to the marketed formulation. It is clear that niosomes prepared using Span 60 showed the more amount of PSP permeated, this might be attributed to the transition temperature of the used surfactant, where the high transition temperature of Span 60 made the niosomes in a more packed ordered gel state at the specified permeation temperature $\left(37^{\circ} \mathrm{C}\right)$ as studied by Vora et al., 1998. The marketed formulation showed just $20 \%$ drug release after $6 \mathrm{~h}$ which may be due to its larger molecule weight and thus large molecule size which indicates there may be a problem in the conjunctival absorption of the drug. Thus this problem was overcome by entrapment of PSP in niosomal in situ gel formulation. The size of vesicle was reduced due to its incorporation into niosomes and the release was sustained by in situ gel formulation.

\section{Pharmacodynamic study}

\section{Primary skin irritation test}

The PII of the test sample was calculated to be 0.00 ; no irritation was observed on the skin of the rabbits/rats. The scores for erythema and edema were summed for intact and abraded skin for rabbits at 24 and 72 h, PII was calculated. Based on the sum of the scored reactions divided by 32 (two scoring intervals multiplied by two test parameters multiplied by 8 animals). PII: $0 / 32=0.00$. Under the conditions of this test, the test sample would not be considered a primary skin irritant since the PII was less than 5.00.

\section{In vivo draize eye irritation test}

The possibility of eye irritation due to niosomal in situ gel administration was evaluated in rabbits. The rabbits were observed for ocular lesions, and no symptoms of ocular irritation such as redness, tearing, inflammation, or swelling were observed after niosomal in situ gel administration. No ophthalmic damage or abnormal clinical signs to the cornea, iris or conjunctivae were visible. Thus, the developed ocular drug delivery systems are apparently free from any ocular irritation potential and can be safely administered to humans. The scores were calculated according to Draize scale.

\section{Pharmacokinetic study}

The aqueous humor concentration $(m e a n \pm S D)$ time profiles of prednisolone sodium phosphate following ocular instillation of optimized niosomal in situ gel (B) and the drug solution in rabbits are depicted in fig. 25 . The differences between the estimated drug pharmacokinetic parameters (Cmax, Tmax, and MRT $(0-8 \mathrm{~h})$ of the two treatments are illustrated in table 15 . The mean $( \pm S D)$ Cmax of the drug solution and that of the optimized formulation (B) were found to be equivalent. The delay in the median Tmax (from 1 to 2 $\mathrm{h})$, as well as the prolongation in the MRT $(0-8 \mathrm{~h})$ from $3.583 \pm 0.526$ to $5.349 \pm 0.035 \mathrm{~h}$ for the drug solution and the optimized formulation respectively, could indicate the sustained-release characteristics of the latter. Based on the calculated $\mathrm{AUC}_{(0-8)}$ value, the increase in the ocular bioavailability was found to be 1.754-fold. The drug penetration enhancement following the instillation of the optimized formulation could be attributed to the presence of surfactant (span 60) in niosomal formulation which also acts as penetration enhancer. In addition to this, PSP being hydrophilic in nature can easily pass the epithelial barrier and thus contribute to increased penetration.

The bioadhesive synthesized polymer macromolecular hydrocolloids have numerous hydrophilic functional groups (carboxylic acid). The cornea and conjunctiva have a negative charge where these mucoadhesive polymers may interact intimately with these extraocular structures [25], would increase the concentration and residence time of the associated drug. The elevated PSP levels in the cornea and aqueous humor following the administration of PSP-Gel might be due to the increase in the amount of PSP dissolved in the precorneal area leading to the high concentration gradient, favoring good permeation, together with higher contact time with the corneal area [63].

\section{Sterility test}

In order to ensure the sterility of the finished product, the final formulation (B) was subjected to the sterility test. The formulation sterilized by membrane filtration method and incubated with different culture media like soybean casein digest medium; fluid thioglycate medium etc., for a period of $14 \mathrm{~d}$ of incubation did not show growth of the organism on the culture medium. This indicated that the formulation was sterile. 


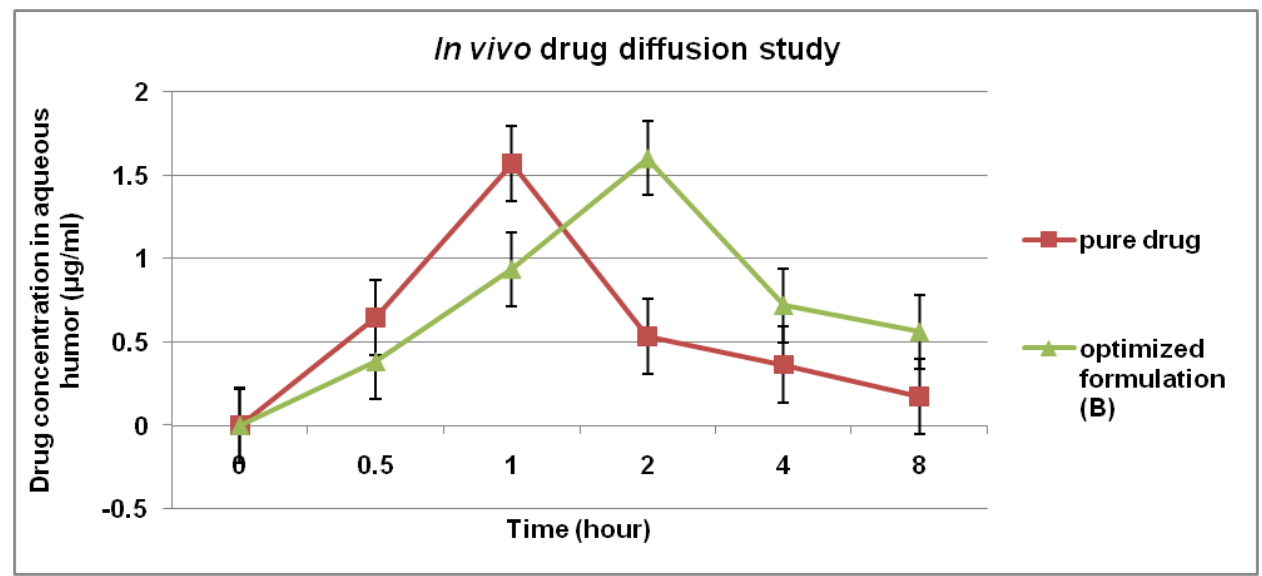

Fig. 25: Aqueous humor concentration-time profiles of PSP following ocular instillation of the drug solution and optimized B formulation to rabbits data expressed mean $\pm S D(n=3)$

Table 15: The pharmacokinetic parameters of PSP following ocular instillation of the drug solution and optimized formulation B to rabbits

\begin{tabular}{|c|c|c|c|c|c|}
\hline Batch & $\mathrm{C}_{\max }(\mu \mathrm{g} / \mathrm{ml})^{*}$ & $\begin{array}{l}T_{\max } \\
\text { (h) }\end{array}$ & $\begin{array}{l}\operatorname{AUC}_{(0-8)} \\
\left(\mu \mathrm{g} \mathrm{h}^{-1} \mathrm{ml}^{-1}\right)^{*}\end{array}$ & $\begin{array}{l}\operatorname{MRT}_{(0-8)} \\
(h)^{*}\end{array}$ & $\begin{array}{l}\text { Increase in bioavailability } \\
\text { (folds) }\end{array}$ \\
\hline Pure drug solution & $1.573 \pm 0.345$ & 1 & $3.75225 \pm 0.254$ & $3.583 \pm 0.526$ & - \\
\hline Optimised formulation (B) & $1.602 \pm 0.427$ & 2 & $6.584 \pm 0.127$ & $5.349 \pm 0.035$ & 1.754 \\
\hline
\end{tabular}

$*($ mean \pm SD, $\mathrm{n}=3)$

Stability study

Accelerated stability study

Table 16: Stability testing by appearance, percent drug content determination and gelation temperature

\begin{tabular}{llll}
\hline $\begin{array}{l}\text { Time } \\
\text { period }\end{array}$ & Appearance & $\begin{array}{l}\text { Percent drug content of optimized } \\
\text { formulation* }\end{array}$ & $\begin{array}{l}\text { Gelation temperature } \\
\left.\mathbf{~}^{\mathbf{0}} \mathbf{C}\right)^{*}\end{array}$ \\
\hline Initial & Translucent & $91.36 \pm 0.36$ \\
After 3 mo & Translucent, little gel formation at the base which can be & $90.53 \pm 0.27$ \\
After 6 mo & converted into sol after shaking & $88.45 \pm 0.47$ & $37.2 \pm 0.23$ \\
\hline
\end{tabular}

$*($ mean $\pm \mathrm{SD}, \mathrm{n}=3)$

The results obtained show that all the formulations were found to contain almost same amount of drug after 6 mo. There was a little decrease in percent drug content but it was less than $5 \%$ for each formulation after 6 mo. The results obtained showed little decrease in the gelation temperature of the formulation with the increase in time but that was so less that it can be neglected (table 16).

Long term stability study

Table 17: Stability testing by appearance, percent drug content determination and gelation temperature

\begin{tabular}{llll}
\hline Time period & Appearance & Percent drug content of optimized formulation & Gelation temperature ( $^{\mathbf{0}} \mathbf{C}^{*}{ }^{*}$ \\
\hline Initial & Translucent & $91.36 \pm 0.36$ & $37.2 \pm 0.23$ \\
After 3 mo & Translucent and stable & $89.53 \pm 0.27$ & $37.1 \pm 0.41$ \\
\hline
\end{tabular}

$*($ mean \pm SD, $\mathrm{n}=3)$

The results obtained showed that all the formulations were found to contain almost same amount of the drug after 3 mo. So it can be concluded that there wasn't any drug loss from formulation during storage. The results obtained showed there wasn't any significant change in the gelation temperature of the formulations after $3 \mathrm{mo}$. So, it can be predicted that the formulation would be stable during storage (table 17).

\section{CONCLUSION}

Different approaches have been used till now in order to overcome the drawbacks related to conventional ocular delivery systems and to improve patient compliance without losing the therapeutic activity of the drug. Niosomal in situ gel proved to be one of the successful approaches to accomplish the goals successfully. Niosomes optimal batch (CS17) was able to entrap PSP where entrapment efficiency was found to be $83.4 \pm 0.22 \%$. As a result, the optimal formula was further incorporated into on situ gel with desirable mucoadhesive behavior essential to achieve increased retention at the target site. The formula exhibited significant permeation with almost 2.5 fold increased flux and sustained for longer periods $(\mathrm{t} 90=10 \mathrm{~h})$ compared to the pure drug and marketed formulation at the same dose level. The pharmacokinetic study in 
rabbits proved that the total concentration of PSP in aqueous humor was higher as compared to that of pure drug solution. The mean residence time and the shift in tmax value indicated sustained release of the drug. Thus niosomal in situ system proved to be a very useful system for ocular drug delivery with promising results.

\section{ACKNOWLEDGMENT}

The authors thank P. E Society's Modern College of Pharmacy, Nigdi, Pune for providing the facilities required for carrying out research work. They also thank UGC for providing funding and fellowship.

\section{AUTHORS CONTRIBUTIONS}

There was an equal contribution of both the authors in carrying out the research work

\section{CONFLICT OF INTERESTS}

There is no conflict of interest

\section{REFERENCES}

1. Rathore KS, Nema RK. An insight into the ophthalmic drug delivery system. Int J Pharm Sci Drug Res 2009;1:1-5.

2. Shell JW, Baker R. Diffusional systems for controlled release of drugs to the eye. Ann Ophthalmol 1974;6:1037-43, 1045.

3. Bourlais CL, Acar L, Zia H, Sado PA, Needham T, Leverge R. Ophthalmic drug delivery systems-recent advances. Pro Retin Eye Res 1998;17:35-58.

4. Kaur IP, Kanwar M. Ocular preparations: the formulation approach. Drug Dev Ind Pharm 2002;28:473-93.

5. Almeida H, Amaral MH, Lobao P, Sousa Lobo JM. Applications of poloxamers in ophthalmic pharmaceutical formulations: on overview. Expert Opin Drug Delivery 2013;10:1223-37.

6. Sasaki H, Yamamura K, Nishida K, Nakamura J, Ichikawa M. Delivery of drugs to the eye by topical application. Prog Ret Eye Res 1996;15:583-620.

7. Nirmal HB, Bakliwal SR, Pawar SP. In-situ gel: new trends in controlled and sustained drug delivery systems. Int J Pharm Tech Res 2010;2:1398-408.

8. Agarwal KI, Mehta N, Namdev A, Gupta AK. In-situ gel formation for ocular drug delivery systems: an overview. Asia J Bio Pharm 2010;1:1-7.

9. Champalal KD, Sushilkumar P. Current status of an ophthalmic in-situ forming hydrogel. Int J Pharm Bio Sci 2012;3:372-88.

10. Shell JW. Ophthalmic drug delivery systems. Surv Ophthalmol 1984;29:117-28.

11. Burstein NL, Anderson JA. Review: corneal penetration and ocular availability of drugs. J Ocul Pharmacol 1985;1:309-26.

12. Modi KA, Shelat PK. Applications of novel vesicular drug delivery system as ocular drug vehicles: a review. Int J Pharm Sci Res 2012;3:4554-61.

13. Sirbat D, Heussler LM, Hoffman M, Maincent P. Ways to improve ocular bioavailability for topical applications. J Fr Opthalmol 2000;23:505-9.

14. Kaur IP, Smitha R. Penetration enhancers and ocular bioadhesives: two new avenues for ophthalmic drug delivery. Drug Dev Ind Pharm 2002;28:353-69.

15. Gupta A, Singh S, Kotla NG, Webster TJ. Formulation and evaluation of a topical niosomal gel containing a combination of benzoyl peroxide and tretinoin for antiacne activity. Int $\mathrm{J}$ Nanomed 2015;10:171-82.

16. Saettone MF, Chetoni P, Cerbai R, Mazzanti G, Braghiroli L. Evaluation of ocular permeation enhancers: in vitro effects on corneal transport of four betablockers, and in vitro/in vivo toxic activity. Int J Pharm 1996;142:103-13.

17. Carafa M, Santucci E, Alhaique F, Coviello T, Murtas E, Riccieri FM, et al. Preparation and properties of new unilamellar nonionic surfactant vesicles. Int J Pharm 1996;160:51-9.

18. Aggarwal D, Garg A, Kaur IP. Development of a topical niosomal preparation of acetazolamide: preparation and evaluation. J Pharm Pharmacol 2004;56:1509-17.

19. Aggarwal D, Kaur IP. Improved pharmacodynamics of timolol maleate from a mucoadhesiveniosomal ophthalmic drug delivery system. Int J Pharm 2005;290:155-9.
20. Liaw J, Robinson JR. Ocular penetration enhancers. In: Mitra AK. editor. Ophthalmic drug delivery systems. Marcel Dekker: New York; 1993. p. 369-81.

21. Sasaki H, Igarashi $Y$, Nagano $T$, Yamamura $K$, Nishida $K$, Nakamura J. Penetration of beta-blockers in albino rabbits. J Pharm Pharmacol 2005;47:17-21.

22. Kaur IP, Smitha R. Penetration enhancers and ocular bioadhesives: two new avenues for ophthalmic drug delivery. Drug Dev Ind Pharm 2002;28:353-69.

23. Tripathi KD. Essentials of medical Pharmacy. 5th ed. India: Jaypee Brothers Medical Publishers; 2004.

24. Aggarwal D, Garg A, Kaur IP. Development of a topical niosomal preparation, of acetazolamide: preparation and evaluation. J Pharm Pharmacol 2004;56:1509-17.

25. Chaudhari PD, Desai US. Synthesis and evaluation of waterinsoluble but swellable polymer for ocular drug delivery. Indian J Pharm Educ Res 2019;53:23-33.

26. Mutha SS, Patel S, Bhopal AV. Thermo reversible niosomal gel as a potential ophthalmic drug delivery system for ganciclovir. Indo Am J Pharm 2013;3:9190-201.

27. Acharya A, Kiran Kumar GB, Ahmed MG, Paudel S. A novel approach to increase the bioavailability of candesartan cilexetil by proniosomal gel formulation: in vitro and in vivo evaluation. Int J Pharm Pharm Sci 2016;8:241-6.

28. Kumar BS, Krishna R, Lakshmi PS, Vasudev DT, Nair SC. Formulation and evaluation of niosomal suspension of cefixime. Asian J Pharma Clin Res 2017;10:194-201.

29. Mohawed O, El Ashmoony MM, Elgazayerly ON. Niosomeencapsulated clomipramine for transdermal controlled delivery. Int J Pharm Pharm Sci 2014;6:567-75.

30. Radha GV, Sastri KT, Prathyusha P, Bhanu P, Rajkumar J. Formulation and evaluation of aceclofenac proniosome loaded orabase for management of dental pain. Int J Appl Pharm 2018;10:204-10.

31. Asthana SG, Sharma PK, Asthana A. In vitro and in vivo evaluation of niosomal formulation for controlled delivery of clarithromycin. Scientifica 2016. Doi:10.1155/2016/ 6492953.

32. Zaki NM, Awad GA, Mortada ND, Abd Elhady SS. Enhanced bioavailability of metoclopramide $\mathrm{HCl}$ by intranasal administration of a mucoadhesive in situ gel with modulated rheological and mucociliary transport properties. Eur J Pharm Sci 2007;32:296-307.

33. Nikam PM, Gondkar SB, Saudagar RB. Formulation development and evaluation of $\mathrm{pH}$-dependent brimonidine tartrate in-situ ophthalmic gel. World J Pharm Pharm Sci 2016;5:1682-703.

34. Hue HW, Robinson JR. Ocular delivery of progesterone using a bioadhesive polymer. Int J Pharm 1985;26:203-13.

35. Land Gel SS, Oswald RJ, Searle AS, Andre RV, Patel SY. Synthesis and evaluation of some novel theorems as mucoadhesive polymer. Der Parma Chemical 2012;4:1385-96.

36. Draize JH, Woodward G, Calvary HO. Methods for the study of irritation and toxicity of substances applied topically to the skin and mucus membranes. J Pharmacol Ext Ther 1944;82:377-90.

37. Abraham MH, Kumar Singh, Cometto-Muniz, Cain WS. Draize eye scores and eye irritation thresholds in man combined into one quantitative structure-activity relationship. Toxicol In Vitro 1998;12:403-8.

38. Musson DG, Bidgood AM, Olejnik O. Comparative corneal penetration of prednisolone sodium phosphate and prednisolone acetate in NZW rabbits. J Ocul Pharmacol 1991; 7:175-82.

39. Tayel AS, El-Nabarawi MA Tadros, Abd-Elsalam WH. Positively charged polymeric nanoparticle reservoirs of terbinafine hydrochloride: preclinical implications for controlled drug delivery in the aqueous humor of rabbits. AAPS PharmSciTech 2013;14:783-93

40. ICH Harmonised tripartite guideline, stability testing of new drug substances and products Q1A (R2); 2003. p. 1-24.

41. Shatalebi MA, Mostafavi A, Moghaddas A. Niosome as a drug carrier for topical delivery of $\mathrm{N}$-acetyl glucosamine. Res Pharm Sci 2010;5:107-17. 
42. Abdelkader H, Adam WG, Alany G. Recent advances in nonionic surfactant vesicles (niosomes): self-assembly, fabrication, characterization, drug delivery applications and limitations. Drug Delivery 2014;21:35-45.

43. Uchegbu IF, Vyas SP. Non-ionic surfactant based vesicles (niosomes) in drug delivery. Int J Pharm 1998;172:33-70.

44. Kumar GP, Rajeshwarrao P. Nonionic surfactant vesicular systems for effective drug delivery an overview. Acta Pharma Sinica B 2011;1:208-19.

45. Panda N, Panda KC, Reddy AV, Subbareddy GV, Patro LR. Formulation design and in vitro evaluation studies of matrix diffusion controlled glipizide transdermal patch. J Phys Chem 2013;7:9-15

46. DL Pavia, GM Lapman, GS Kriz. Inroduction to spectroscopy. third edition. Thomson learning Inc. 2001. p. 26.

47. Yadav K, Yadav D, Saroha K, Nanda S, Mathur P, Syan N Proniosomal gel: a provesicular approach for transdermal drug delivery. Der Pharma Lett 2010;2:189-98.

48. Honary SE, Ebrahimi P, Tabbakhian M, Zahir F. Formulation and characterization of doxorubicin nanovesicles.J Vac Sci Technol B Microelectron Nanometer Struct 2009;27:1573-7.

49. Sezgin Bayindir Z, Yuksel N. Investigation of formulation variables and excipient interaction on the production of niosomes. AAPS PharmSciTech 2012;13:826-35.

50. Zhang Z, Feng SS. Self-assembled nanoparticles of poly (lactide)-vitamin E TPGS copolymers for oral chemotherapy. Int J Pharm 2006;324:191-8.

51. Liu S, Jones L, Gu FX. Nanomaterials for ocular drug delivery. Macromol Biosci 2012;12:608-20.

52. Ali Y, Lehmussaari K. Industrial perspective in ocular drug delivery. Adv Drug Delivery Rev 2006;57:1258-68.

53. Hamsika M, Gowda DV, Vindru J, Moin A. Nanotechnology for ophthalmic preparations. Int J Curr Pharm Res 2016;8:5-11.
54. Okore VC, Attama AA, Ofokansi KC, Esimone CO, Onuigbo EC. Formulation and evaluation of niosomes. Indian J Pharm Sci 2011;73:323-8.

55. Win KY, Feng SS. Effects of particle size and surface coating on cellular uptake of polymeric nanoparticles for oral delivery of anticancer drugs. Biomaterials 2005;26:2713-22.

56. Dumortier G, El Kateb N, Sahli M, Kedjar S, Boulliat A, Chaumeil JC. Development of a thermogelling ophthalmic formulation of cysteine. Drug Dev Ind Pharm 2006;32:63-72.

57. Yong CS, Choi JS, Quan Q, Jong-Dal R, Kim C, Lim S, et al. Effect of sodium chloride on the release, absorption, and safety of diclofenac sodium delivered by poloxamer gel. Int J Pharm 2001;263:195-205.

58. Baloglu E, Karavana SY, Zeynep AY, Guneri T. Rheological and mechanical properties of poloxamer mixtures as a mucoadhesive gel base. Pharm Dev Technol 2010;16:627-36.

59. Badgujar SD, Sontakke MA, Narute DR, Karmarkar RR, Tupkar SV, Barhate SD. Formulation and evaluation of sumatriptan succinate nasal in situgel using fulvic acid as a novel permeation enhancer. Int J Pharm Res Dev 2010;2:1-8.

60. Abdel Mottaleb MM, Mortada ND, Elshamy AA, Awad GA Preparation and evaluation of fluconazolegels. Egypt J Biomed Sci 2007;23:266-86.

61. Bourlais CL, Acar L, Zia H, Sado PA, Needham T, Leverge R. Ophthalmic drug delivery systems-recent advances. Prog Ret Eye Res 1998;17:33-58.

62. Dhiman M, Yedurkar P, Sawant KK. Formulation, characterization and in vitro evaluation of bioadhesive gels containing 5-Fluorouracil. Pharm Dev Tech 2008;13:15-25.

63. Abdelbary GA, Amin MA, Zakaria MY. Ocular ketoconazoleloaded proniosomal gels: formulation, ex vivo corneal permeation and in vivo studies. Drug Delivery 2017;24:309-19. 